\title{
Д.
}

\section{Strawberry taste assessment during shelf life}

F.I. Pereira da Silva

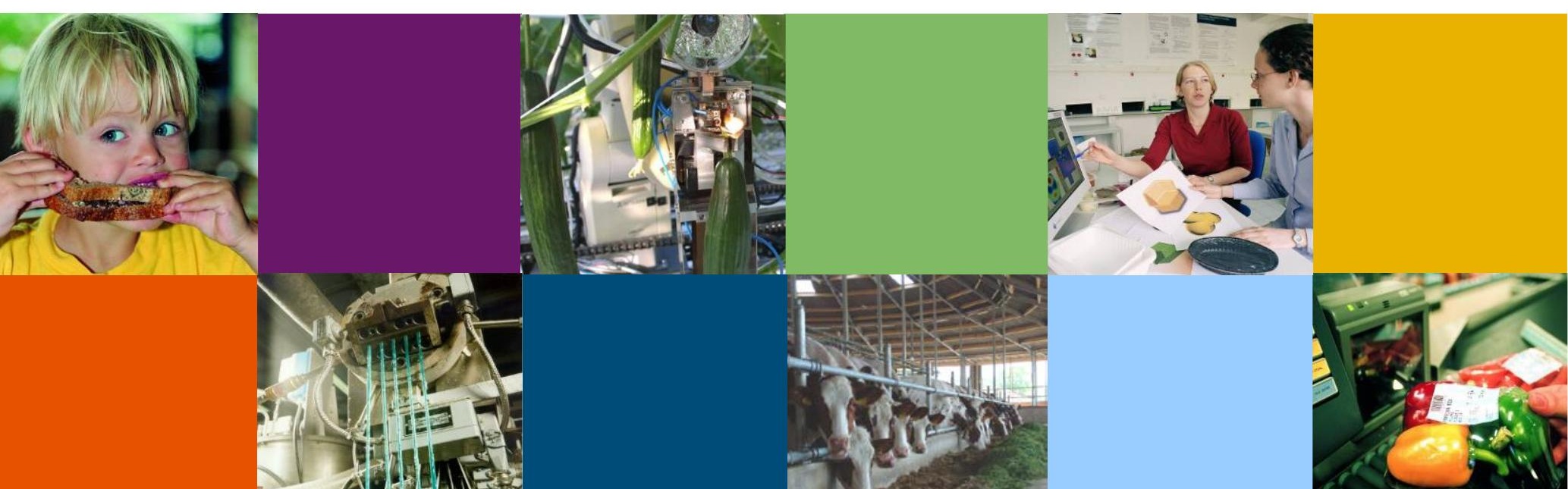




\section{Colophon}

Title Strawberry taste assessment during shelf life

Author(s) F.I. Pereira da Silva

Number $\quad 1776$

Doi $\quad$ https://doi.org/10.18174/503222

Date of publication $\quad 6$ November 2017

Version Final

Confidentiality No

Approved by Bastiaan Brouwer

Review Intern

Name reviewer Janneke de Kramer

Sponsor Foundation TKI Horticulture

Client Driscoll's and Bakker Barendrecht

Wageningen Food \& Biobased Research

P.O. Box 17

NL-6700 AA Wageningen

Tel: +31 (0)317480084

E-mail: info.fbr@wur.nl

Internet: www.wur.nl/foodandbiobased-research

(C) Wageningen Food \& Biobased Research, institute within the legal entity Stichting Wageningen Research All rights reserved. No part of this publication may be reproduced, stored in a retrieval system of any nature, or transmitted, in any form or by any means, electronic, mechanical, photocopying, recording or otherwise, without the prior permission of the publisher. The publisher does not accept any liability for inaccuracies in this report. 


\section{Abstract}

Strawberry quality is largely dependent on the ripeness stage at harvest. Another important aspect of quality is the time of storage after harvest. The longer the storage time, the greater the loss of quality. Strawberry flavour is an important quality feature and largely dependent on aroma volatiles. Expert panels have been used to assess taste and flavour, but show variation in the range of scores of taste and flavour attributes. Moreover expert panels require a high number of panellists, are time consuming and expensive. Alternative techniques are therefore interesting and useful. PTR Qi-TOF (Proton Transfer Reaction Quadrupole interface Time-Of-Flight Mass Spectrometry) is a device for real-time detection of volatiles. The technique is fast, simple, does not require much sample preparation and is sensitive to a wide range of aroma volatiles. Hence the PTR-Qi-TOF may be suitable to measure flavour and taste. Moreover the combination of the strengths of both techniques can add relevant insights in the understanding and assessment of this important quality feature.

The aim of this study was to investigate whether the PTR Qi-TOF could measure important volatiles in taste and flavour perception and whether the PTR Qi-TOF could replace the expert panel assessment. Another goal of this work was to gain insight in the effect of maturity stage on taste and flavour perception and how taste/flavour changes during shelf life.

The main conclusion of this work are:

- The PTR spectra correlate well with the expert panel. A number of volatiles measured with the PTR are linked to specific taste and flavour attributes measured by the expert panel;

- The effect of the maturity stage on taste and flavour is far stronger than the storage time;

- An optimal maturity at harvest is essential to obtain high quality tasting strawberries;

- The flavour and taste of unripe strawberries does not improve during shelf life and never reaches the scores level of ripe strawberries;

- Some positive flavour and taste attributes of ripe strawberries clearly decrease during shelf life.

Two ripeness levels (ripe and unripe) and three storage times (day 1, 5 and 9 after harvest) were analysed to study their effect on volatiles detected by PTR Qi-TOF and taste/flavour perception scored by an expert panel. Clear differences between ripeness level and storage time were found with both the PTR Qi-TOF and the expert panel. Ripe strawberries were correlated with pleasant fruity aromas, sweetness and an abundance of volatile masses, while unripe strawberries were more correlated with green aroma, sourness, firmness and with less volatile masses. The measurement of volatiles is particularly interesting as this assessment is objective. 
Based on these results it can be concluded that the PTR spectra correlates well with the expert panel scores. The taste and flavour attributes sweetness, strawberry aroma, aroma presence and green aroma showed the highest correlation coefficients (R-square ranging from 0.80 to 0.61 ) indicating that the correlation between the PTR spectrum and these attributes is very reasonable. Despite the shortcomings in the data that may lead to an overestimation of the results, this work has shown the potential of this application and is a first step into the development of a new objective technique to predict taste and flavour using PTR Qi-TOF.

Additionally this study has shown that the maturity stage at harvest leads to clear distinct flavour/taste profiles. Positive attributes score higher by ripe strawberries indicating that optimal mature strawberries should result in a more pleasant taste and flavour perception. Moreover the changes in flavour and taste perception over the shelf life are rather different for ripe and unripe strawberries. Ripe strawberries lose strawberry aroma and are less liked. The score of strawberry aroma, fruity aroma, aroma presence and likening of unripe strawberries does not increase over storage time. The taste and aroma perception of unripe strawberries does not improve during shelf life and never reaches the scores level of ripe strawberries. This shows that the maturity stage at harvest is essential to achieve high quality tasting strawberries. 


\section{Content}

$\begin{array}{ll}\text { Abstract } & 3\end{array}$

1 Introduction $\quad 6$

1.1 Background 6

$\begin{array}{lll}1.2 & \text { Aim and research questions } & 7\end{array}$

$\begin{array}{lll}1.3 & \text { GreenCHAINge project } & 7\end{array}$

2 Methods $\quad 8$

2.1 Plant material, test variables and set up $\quad 8$

2.2 Volatiles 9

2.3 Taste and flavour assessment 9

$\begin{array}{lll}2.4 & \text { Visual quality inspection } & 10\end{array}$

2.5 Colour and firmness 10

2.6 SSC and acid 11

2.7 Taste model measurements and taste evaluation industry 11

$\begin{array}{lll}2.8 \text { Data analysis } & 12\end{array}$

3 Results 13

3.1 Taste and flavour assessment by expert panel 13

3.2 Volatiles measurement (PTR-Qi-TOF) and taste 15

3.3 Other quality aspects 19

3.4 Taste and other quality aspects 24

3.5 Taste model measurements and taste evaluation industry 27

4 Discussion $\quad 28$

5 Conclusions and further research 33

$\begin{array}{ll}\text { References } & 35\end{array}$

$\begin{array}{ll}\text { Acknowledgements } & 37\end{array}$

$\begin{array}{ll}\text { Appendices } & 38\end{array}$ 


\section{Introduction}

\subsection{Background}

\section{Strawberry aroma, flavour and taste}

Strawberries (Fragaria $x$ ananassa Duch.) are highly appreciated fruits and known for their unique and delicious flavour. The aroma plays an important role in the flavour and taste perception of strawberries. However, aroma improvement in strawberry is very complex, since strawberries are octoploid fruits and its aroma compounds are produced by different biosynthetic pathways (Schwab et al., 2008; Vandendriessche et al., 2013). Nevertheless the industry recognises the relevance of flavour/taste and more efforts are done to enhance this important but complex quality aspect.

Strawberry flavour is mainly dependent on the presence of sugars, acids and aroma volatiles (Buttery, 1981). While aroma volatiles include only 0.001 to $0.01 \%$ of the strawberry's fresh weight, they highly determine the fruit quality. The strawberry aroma is one of the most complex fruit aromas, in which over 350 different volatiles have been detected. However, a single strawberry does not contain all of these volatiles and even less of these have an influence on strawberry aroma (Schwab et al., 2008; Swieterman et al., 2014; Forney et al., 2000).

Two typical strawberry volatiles that are both highly determined for the strawberry aroma, are the furanones 2,5-dimethyl-4-hydroxy-3 $(2 \mathrm{H})$-furanone (furaneol) and 2,5-dimethyl-4-methoxy-3 $(2 \mathrm{H})$ furanone (mesifurane). They are associated with the characteristic sweet, caramel, floral and fruity aroma of strawberry and increase during ripening (Schwab et al., 2008; Jetti et al., 2007). The majority of aroma compounds is dominated by esters. Important esters are ethyl acetate, methyl butanoate, ethyl butanoate, ethyl isovalerate, methyl hexanoate and ethyl hexanoate, which all contribute to fruity notes. Next to esters, monoterpenoids (C10) and sesquiterpenoids (C15) are also relevant volatile groups characterised by fruity citrus aroma (Schwab et al., 2008). In particular, the monoterpenoid S-Linalool is found to be an important volatile contributing to the general strawberry aroma (Schwab et al., 2008). Other important aroma compounds are the aldehydes hexanal and trans-2-hexenal, and the alcohols 3 heptanol, 1-hexanol and cis-3-hexen-1ol, which contribute to fresh green notes. Furthermore, lactones are linked with fruity, coconut aromas, for example Y-decalactone (Jetti et al., 2007). Volatiles that are derived from the essential amino acids leucine, isoleucine, and phenylalanine, such as phenyl acetaldehyde, 2-phenylethanol, methyl salicylate, and 2- and 3-methylbutanal, are also important flavour compounds of strawberry (Farneti et al., 2012). 


\section{Maturity stage and shelf life}

Fruit quality is largely dependent on the ripeness stage at harvest (Vandendriessche et al., 2013). Ripe fruits have a higher sugar-to-acid ratio and produce more aroma volatiles. Another important aspect in fruit quality is the time of storage after harvest. The longer the storage time, the greater the loss of characteristic aroma volatiles and the more off-odour will be produced, which are often correlated with ethanol, acetaldehyde and ethyl acetate accumulation. This could be slowed down to a certain extent by lower temperatures and a controlled atmosphere (Kader, 1991; Pelayo-Zaldivar et al., 2005).

\section{Taste and flavour assessment}

In order to improve strawberry flavour, taste and flavour perception has to be measured. So far, flavour has been assessed using expert panels. Although expert panels are trained for specific products, they show variation in the range of scores of taste attributes depending on how familiar they are with certain varieties (Jaeger et al., 2017). Moreover, expert panels require a high number of panellists, are time consuming and thus expensive. Alternative techniques are therefore interesting and useful.

\subsection{Aim and research questions}

PTR Qi-TOF MS (Proton Transfer Reaction Quadrupole interface Time-Of-Flight Mass Spectrometry) is a device for real-time detection of volatiles (Ionicon, 2016). The technique is fast, simple, does not require much sample preparation and is sensitive to a wide range of aroma volatiles. As a result, the PTR-Qi-TOF may be suitable to measure flavour and taste.

The aim of this study was to investigate whether the PTR Qi-TOF could measure important volatiles in taste perception and whether the PTR Qi-TOF could replace a trained expert panel. If the PTR spectrum can be linked to taste perception, then using PTR Qi-TOF is a more objective and reliable method to detect these taste attributes and measure taste perception.

In addition, this study will give insight in the following questions:

1. How does flavour and taste change over shelf life?

2. How does the initial maturity stage affect changes in flavour and taste?

\subsection{GreenCHAINge project}

This research is part of the GreenCHAINge project. GreenCHAINge is a large project carried out by Wageningen UR Food \& Biobased Research together with a number of industrial partners. The overall goal of the project is to understand and improve the quality of fresh fruits and vegetables throughout the production and distribution chain. The project is divided in subprojects focussing on different products and production chains. The research work reported in this document has been carried out within sub-project 3; soft fruit. 


\section{Methods}

\subsection{Plant material, test variables and set up}

Strawberries (var. Lusa) were obtained from Driscoll's (Prinsenbeek, the Netherlands). They were grown in a test plot under the same growing conditions. The strawberries were picked at two ripeness levels: ripe, and unripe. Ripeness levels were determined visually by the level of red colour (Figure 1.1). On May $10^{\text {th }}$ strawberries were harvested and transported to Food \& Biobased Research (Wageningen, the Netherlands), where they were immediately stored at $4{ }^{\circ} \mathrm{C}$ and $80 \%$ relative humidity $(\mathrm{RH})$.

Measurements were performed on day 1, 5 and 9 after harvest, on May $11^{\text {th }}, 15^{\text {th }}$ and $19^{\text {th }}$ respectively. In this way 6 treatments were analysed by varying 2 factors: 1 . Ripeness level (ripe or unripe); and 2. Storage time (day 1, day 5 or day 9 after harvest).
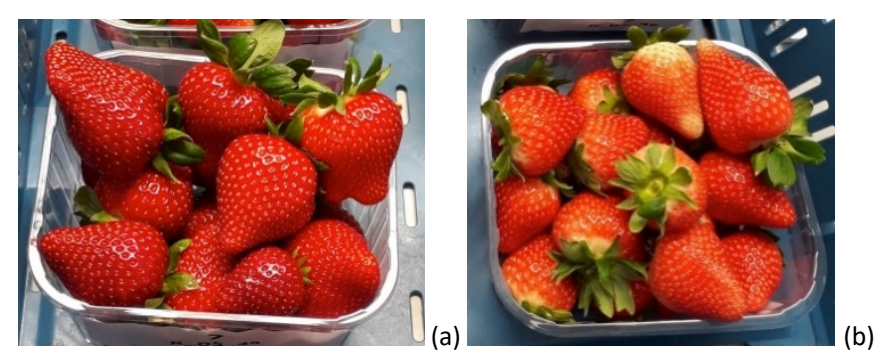

Figure 1.1. Ripe and unripe strawberry punnets of $500 \mathrm{~g}$. (a) Ripe punnet; (b) Unripe punnet.

A PTR QI-TOF instrument was used for volatile detection and a trained expert panel to assess taste and flavour. In addition flavour/taste model measurements were carried out for the calculation of a taste score based on the taste model developed by Wageningen Plant Research (Bleiswijk, The Netherlands). Besides these measurements other fruit characteristics were also measured, including appearance, decay, colour, firmness, Soluble Solid Content (SSC) and acid concentration. All measurements were performed at room temperature. The day before the measurements, the punnets were moved from the $4{ }^{\circ} \mathrm{C}$ storage cell and placed into a "warm-up cell'. Six hours prior to the start of the measurements the strawberries were warmed up to $20^{\circ} \mathrm{C}$. Each of the 6 treatments was analysed using 11 samples. Five samples per treatment were used for volatile detection and taste perception, each sample consisting of 4 punnets of $500 \mathrm{~g}$ strawberries. Likewise, 5 samples per treatment were used to measure other fruit characteristics, each sample consisting of 1 punnet of $500 \mathrm{~g}$ strawberries. Finally, 1 sample per treatment was used for the taste model measurements. This 1 sample consisted of 4 punnets with $500 \mathrm{~g}$ each. All punnets were weighed on day 0 and their day of measurement. 
Additionally, a taste evaluation and measurements of other quality aspects were also carried out at both Driscoll's and Bakker Barendrecht. Both companies used strawberries from the same lot and origin as for the measurements described above. The punnets were stored by both companies under the same conditions $\left(4^{\circ} \mathrm{C}\right.$ and $\left.80 \% \mathrm{RH}\right)$ and were evaluated on the same days: day 1 , day 5 and day 9 after harvest.

\subsection{Volatiles}

Volatile masses were detected with a PTR Qi-TOF MS (Ionicon, Innsbruck, Austria). This is a device for fast real-time detection of volatiles by using hydronium $\left(\mathrm{H}_{3} \mathrm{O}^{+}\right)$ions in gas phase as ion source reagents (Blake et al., 2009; Ionicon, 2016; Further details in appendix). The 4 punnets per sample allocated for volatile detection and taste assessment were divided over 2 drums (Figure 1.2a) and flushed with medical air for 2 minutes. Forty-five minutes after flushing, each drum was connected to the PTR (Figure 1.2b) to acquire fingerprints of the mass spectrum. The individual signals (counts per second; cps) were corrected for the baseline of carbon-filtered air, the accumulation time and the sample weight. The two fingerprints per sample were averaged after analysis.
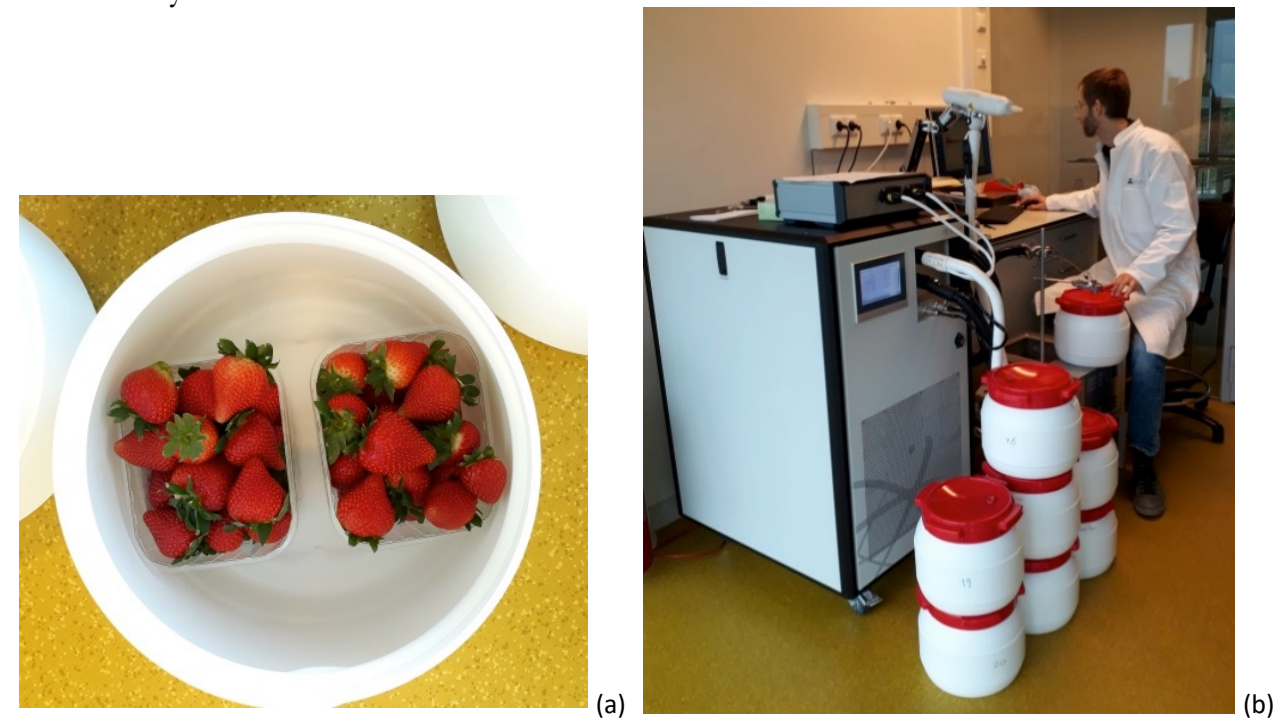

Figure 1.2. Volatile detection. (a) Per drum two punnets of one sample; (b) PTR Qi-TOF measurements.

\subsection{Taste and flavour assessment}

After volatile detection, the same samples were transported to Bleiswijk, the Netherlands to be evaluated by a trained expert panel (Greenhouse Horticulture, Bleiswijk, the Netherlands). This expert panel trained for strawberries (var. Lusa) scored the samples for several taste attributes to establish taste and flavour profiles. Nineteen panellists scored 6 strawberry pieces per sample in individual booths illuminated with red light during an afternoon and an early evening session. Samples were mixed and the evening samples were stored at $15^{\circ} \mathrm{C}$ until 3 hours prior to the measurement. Samples were tasted at room temperature. Per sample, a single taste profile was obtained. 
Twenty-one taste attributes were scored on a 100-point scale: aroma presence, aroma likening, fruity aroma, fruity strawberry aroma, fruity berry aroma, fruity other aroma (specific fruity associations notated), flower aroma, green aroma, musty aroma, yeast, bitter, astringent, greasy filming, prickling, firmness, firmness of the seeds, mealiness, fibred, juiciness, sweetness and sourness. In general the term "taste" is used in this report meaning both flavour and taste features. The trained expert panel has assessed both flavour (wide range of aroma's) and taste (bitterness, sweetness, etc) attributes.

\subsection{Visual quality inspection}

The visual quality was scored on 5 samples per treatment. The appearance per sample was scored on a 9-point scale (Karlruher Scheme, appendix) and off-odours were noted down. Calyx appearance and decay of the outer skin were scored for each individual strawberries per sample. The appearance of the calyx was scored as either: 0 . No spots or folds and looks fresh green; 1 . One brown spot, light yellow; 2. More brown spots, yellow; 3. $>50 \%$ of leaves are changed in colour, brown and/or visible mould growth. The decay of the outer skin was scored as either: 0 . No bruises; 1 . One dry bruise; 2 . One wet bruise or 2 or more dry bruises; 3 . Two or more wet bruises; 4. Mould formation; 5. > 50\% covered with mould (Figure 1.3). The scores for the individual strawberries were averaged to obtain a score per punnet.

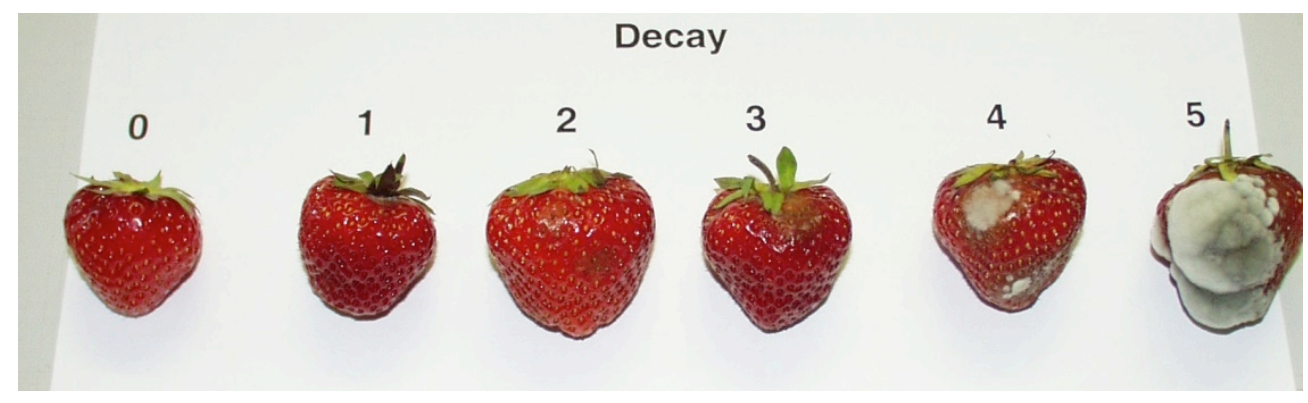

Figure 1.3. Decay score classes of the outer skin on a 0-5 scale.

\subsection{Colour and firmness}

From each sample, 15 individual strawberries had their calyx removed and placed on a numbered grid to measure both colour and firmness. Colour measurements were executed on each strawberry on two sides by using a RGB camera (MAKO G-192C POE, Allied Vision, Stadtroda, Germany) positioned in a LED light cabinet that was calibrated using a colour reference card. Image analysis was done using colour space and colour recognition software (WFBR, Wageningen, the Netherlands) to single out the strawberries and assess Hue colour values. Firmness measurements were done using a Firmtech FT7 instrument (UP Umweltanalytische Produkte GmbH, Ibbenbüren, Germany) on the same 15 strawberries. The instrument was set (strawberry settings) and calibrated. The diameter and the firmness $\left(\mathrm{g} \mathrm{mm}^{-1}\right)$ were measured for each strawberry individually. 


\subsection{SSC and acid}

These measurements were performed on the same 15 strawberries per sample used for the colour and firmness assessment. For SSC and acid sample preparation the strawberries were cut into two halves. One half of the total strawberries per sample was frozen in liquid nitrogen for eventual extra analysis. The other half was used to make a juice, using a juice press, for the SSC and acid measurements. The first part of the flow was not taken to avoid residue of prior samples. Only $30 \mathrm{~mL}$ of the middle part of the flow was collected. The juice was centrifuged for 10 minutes at $4.700 \mathrm{rpm}$ to obtain a supernatant without particles. The supernatant was transferred to a new tube, which became the non-diluted juice. From this juice a 50x dilution was made by transferring $0.5 \mathrm{~g}$ to a new tube and filling up to $25 \mathrm{~g}$ with demineralized water (demi water) by using a pipette.

A pocket Brix-Acidity meter PAL-BX |ACID F5 (ATAGO, Tokyo, Japan) was used to measure Soluble Solids Content (SSC) and acid\%. The SSC was measured in ${ }^{\circ}$ Brix. One degree Brix is equal to $1 \mathrm{~g}$ of sucrose per $100 \mathrm{~g}$ solution. The acid $\%$ was measured through electrical conductivity. In the case of strawberries the instrument assesses the amount of citric acid in the solution (through electrical conductivity). In strawberry the primary acid is namely citric acid (Perkins-Veazie, 1995). The PAL-BX|ACID F5 instrument can measure several fruits, including citrus, grape and wine, tomato, strawberry, and blueberry. Each fruit has its own settings to perform the measurements. The measurement range for SSC is 0 to $60^{\circ} \mathrm{Brix}$ for all fruits, but the measurement range for acid $\%$ is different for each fruit, and is 0.1 to $3.5 \%$ for strawberry. The instrument was set to zero by dropping demi water on the sensor. Prior to starting the measurements the solutions were stirred well. The SSC was measured by dropping $0.2 \mathrm{~mL}$ of the non-diluted juice on the sensor. For measuring the acid $\%$ at least $0.6 \mathrm{~mL}$ of the $50 \mathrm{x}$ diluted solution was taken. Between each measurement the sensor was cleaned with demi water and dried with tissue paper. Each sample was measured in duplicate.

\subsection{Taste model measurements and taste evaluation industry}

Wageningen Plant Research (Bleiswijk, The Netherlands) developed a taste model to assess the taste and flavour level of strawberries. This predictive model works with a number of input parameters for basic flavour characteristics that are measured in the laboratory and gives a taste score on a scale from 1 to 100 (the higher the score the better the flavour/taste). The necessary measurements and calculations were carried at Wageningen Plant Research (Bleiswijk, The Netherlands). The samples for these taste model measurements were transported to Bleiswijk together with samples for the expert panel. 
A taste evaluation and measurement of other quality aspects was also carried out by Driscoll's and Bakker Barendrecht. Both companies used strawberries from the same lot and origin as for the measurements described above. The punnets were stored by both companies under the same conditions and evaluated on the same days: day 1, day 5 and day 9 after harvest. The companies used their current protocols. The taste evaluation is based on a score between 1 and 10, where 1 is not pleasant and 10 is very pleasant.

\subsection{Data analysis}

The data was collected using Excel. Statistical analyses were performed using Unscrambler (Camo, Oslo, Norway) for Principal component analysis (PCA) and Partial least squares (PLS) regression mainly to assess relations between volatile masses detected by PTR Qi-TOF and the taste and flavour profiles by the expert panel (more PCA and PLS information in appendix). GenStat 18.1 (VSNi, Hemel Hempstead, UK) was used to perform one-way and two-way Analysis of variance (ANOVA) on the non-spectral data (the non-PTR-Qi-TOF data): one way ANOVA was used to find differences in storage time per ripeness and a two way ANOVA to investigate the effects of ripeness and storage time and their interaction. 


\section{Results}

In this session the results of taste and flavour scores will be presented first, followed by the PTRQi-TOF-MS data. Subsequently these results will be combined and analysed. The other quality aspects measured will be presented and also related to the taste and flavour scores. Finally the results of the taste model measurements and the taste score of the companies will presented. In general the term "taste" is used in this report meaning both flavour and taste features. The trained expert panel has assessed both flavour (wide range of aroma's) and taste (bitterness, sweetness, etc.) attributes.

PCA was used to explore the variation in the mass spectra of the volatile profiles and taste perception for the different samples. A PLS was applied to correlate the mass spectra with taste perception.

For the taste attributes and other quality measurements an ANOVA was used to find differences in the effects of ripeness and storage time, their interactions and storage time per ripeness. In the two way ANOVA no equal variances were found for appearance $(p=0.001)$, hue white $(p<0.001)$ and area white $(p=0.003)$. In the one way ANOVAs for taste attributes no equal variances were found for sourness $(p=0.011)$, aroma likening $(p=0.016)$ and yeast $(p=0.021)$ for ripe strawberries and for fibred $(\mathrm{p}=0.034)$ for unripe strawberries. Log transformation did not improve the equal variance. Since ANOVA is quite robust, it was chosen to perform the tests, but the results for these variables are less reliable.

\subsection{Taste and flavour assessment by expert panel}

Figure 3.1 shows the scores of 21 sensorial attributes averaged over the three measurement days both for the ripe and unripe strawberries. 


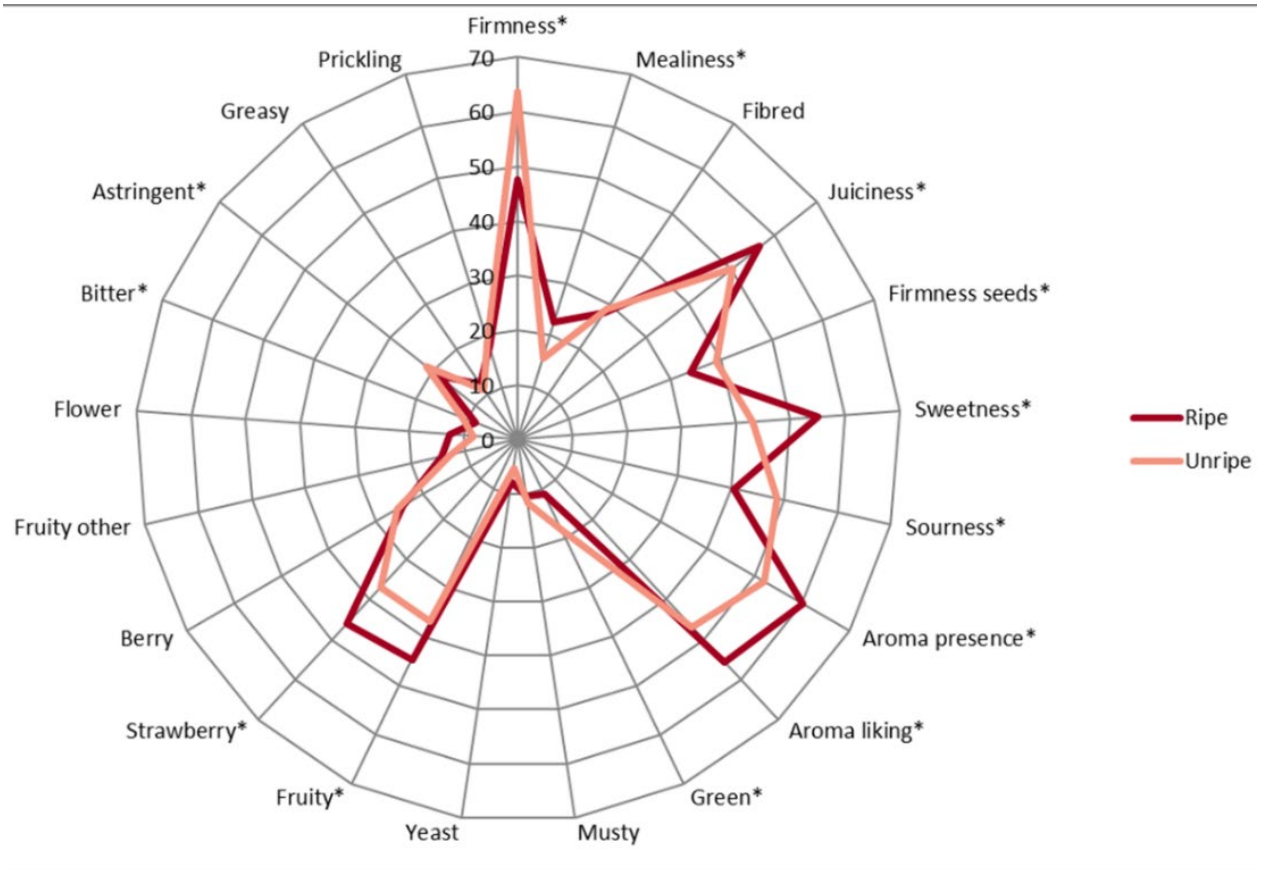

Figure 3.1. Average score over three judgement days per taste attribute for ripe and unripe strawberries ( $n=15)$. In red the ripe and in pink the unripe strawberries. Taste attributes that showed significant differences between ripe and unripe stage are marked with an * $(p=0.05)$.

Ripe strawberries scored higher for mealiness, juiciness, sweetness, aroma presence, aroma liking, fruity aroma and strawberry aroma $(\mathrm{p}=0.05)$. In contrast unripe strawberries scored higher for firmness, firmness seeds, sourness, green aroma, bitter and astringent compared to unipe strawberries $(\mathrm{p}=0.05)$. No significant differences between maturity stages were found for fibred, musty aroma, berry aroma, fruity other aroma, greasy filming and prickling. For the attributes flower aroma and yeast there is an interaction between the two maturity stages and the shelf life.

Figure 3.2 shows how the score of taste attributes changes over the shelf life. For ripe strawberries firmness, aroma likening and strawberry aroma decreased, while musty aroma and yeast increased over storage time. For unripe strawberries sweetness, green aroma and fibred decreased, while mealiness, sourness and prickling increased over storage time (Figure 3.2). 


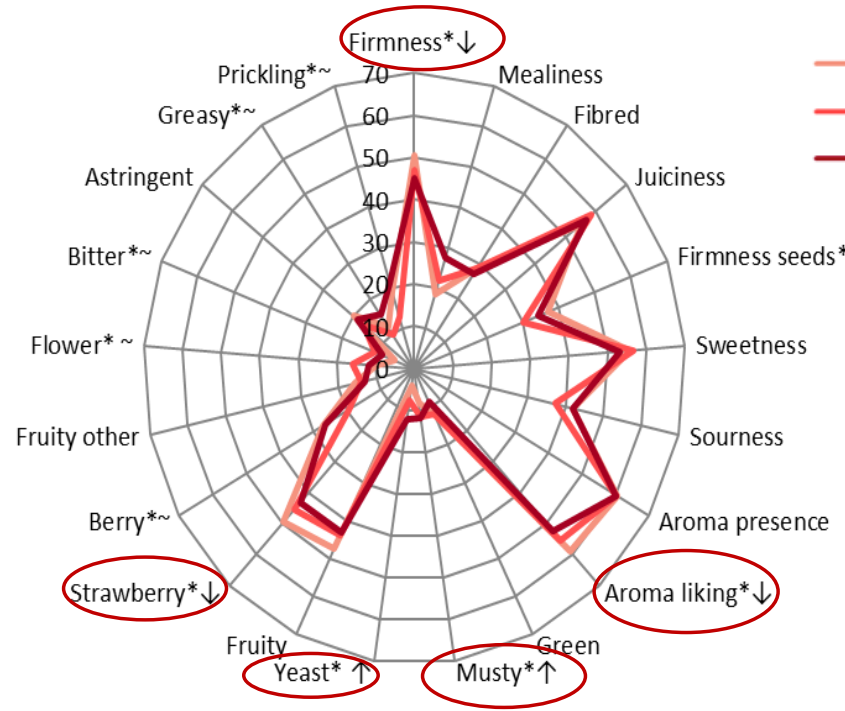

(a)

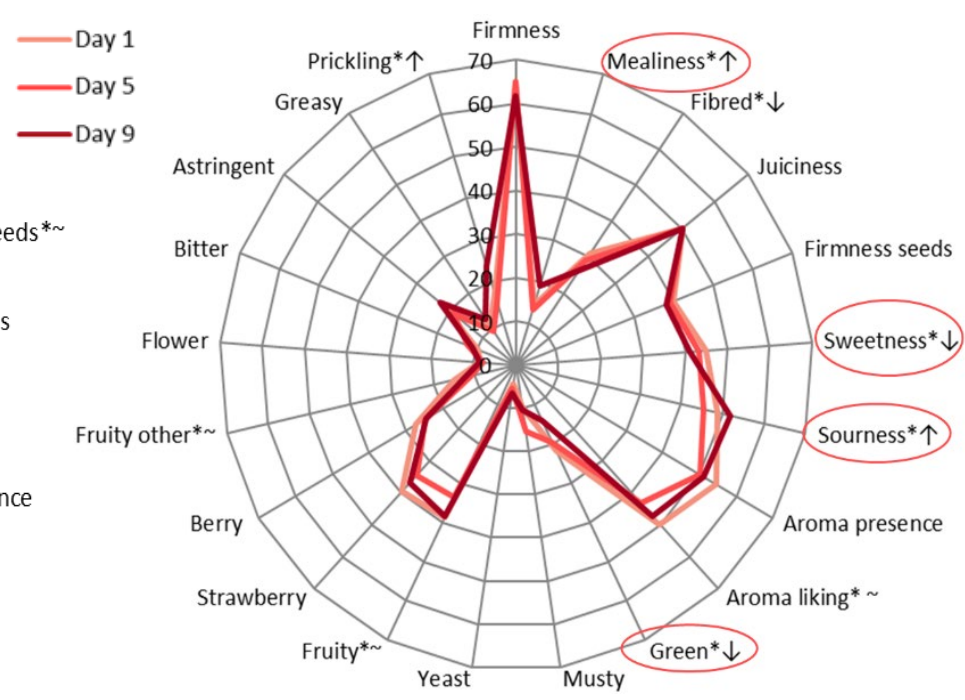

(b)

Figure 3.2. Taste attributes for ripe and unripe strawberries per day $(n=5)$. (a) Ripe strawberries; (b) Unripe strawberries. In light red day 1 , in red day 5 and in dark red day 9 after harvest. Taste attributes that showed significant difference between days are marked with an asterisk $\left({ }^{*}\right)(\mathrm{p}=0.05)$, increase over time is marked with an arrow upwards $(* \uparrow)$, decrease over time is marked with an arrow downwards $\left({ }^{*} \downarrow\right)$. Taste attributes with asterisk and did not show a clear trend.

\subsection{Volatiles measurement (PTR-Qi-TOF) and taste}

Due to the complexity of the spectra, the data was analysed using multivariate analysis (PCA = Principal Components Analysis and PLS = Partial Least Squares). PCA is an algorithm that searches for the similarities and differences between variables within one data matrix. The data is compressed by reducing the number of dimensions without much information loss. Most of the variation in the dataset is explained by principal component (PC) 1 , the second most by PC 2 , and so on. PLS regression analyses the relation between two matrixes.

\section{Volatile masses (PTR spectra)}

In figure 3.3 the mass spectra are visualised for the ripe and unripe strawberries of the average between three judgement days. In general higher peaks were found for ripe strawberries compared to unripe strawberries. 


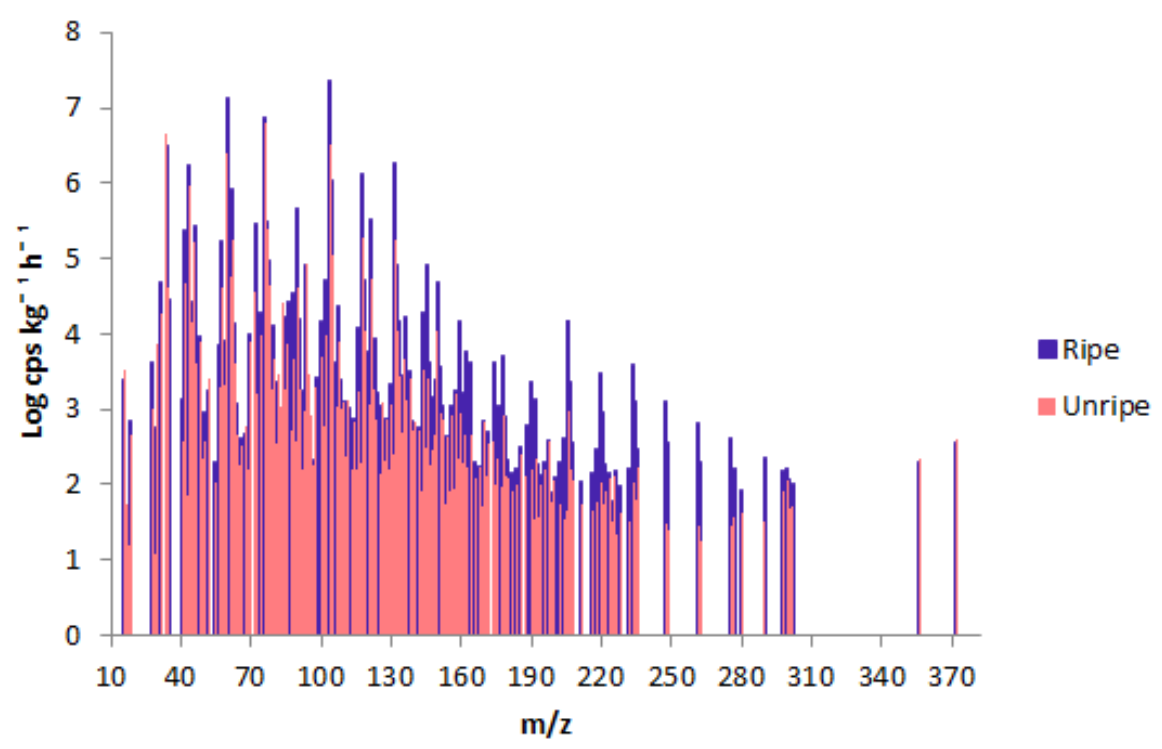

Figure 3.3. The mass spectra of ripe and unripe strawberries averaged between three judgement days. Log counts per second per kg per $\mathrm{h}$ as function of the mass-to-charge ratio is visualised.

Principal component analysis (PCA), performed on the detected masses, showed that most of the variation was explained by ripeness (84\%), resulting in a clear distinction between ripe and unripe strawberries. The second-most variation was explained by differences in storage time (7\%). Furthermore, the correlation loadings plot of the PCA showed that the distribution of masses was concentrated towards ripe strawberries. While the original PCA plots are not shown, the same distribution can be seen in the PLS plots (Figures 3.5 and 3.6).

The molecular masses of strawberry volatiles found in earlier studies were selected and identified in the mass spectra of the average ripe and unripe strawberries. The masses of the molecular formulas of several volatiles, such as esters: ethyl acetate, methyl butanoate, ethyl butanoate, ethyl isovalerate, methyl hexanoate and ethyl hexanoate, furonones: furaneol and mesifurane, aldehydes: trans-2hexenal and trans-2-octenal, terpenoids: linalool and apha-Terpineol, acids: 2-Methylbutanoic acid and hexanoic acid and the alcohol ethanol were present and all higher in ripe strawberries (Figure 3.4). However, a molecular mass of the PTR spectrum may correspond to several volatiles that share the same molecular mass. Table 3.1 shows which volatiles correspond with certain molecular formulas and masses. While the current setup allows for a tentative identification, based on reports of volatiles in strawberries, a fully certain identification would require other techniques, such as GC-MS. Table 5.1 in appendix is shown which masses were expected for the molecular formulas and which masses were found. 


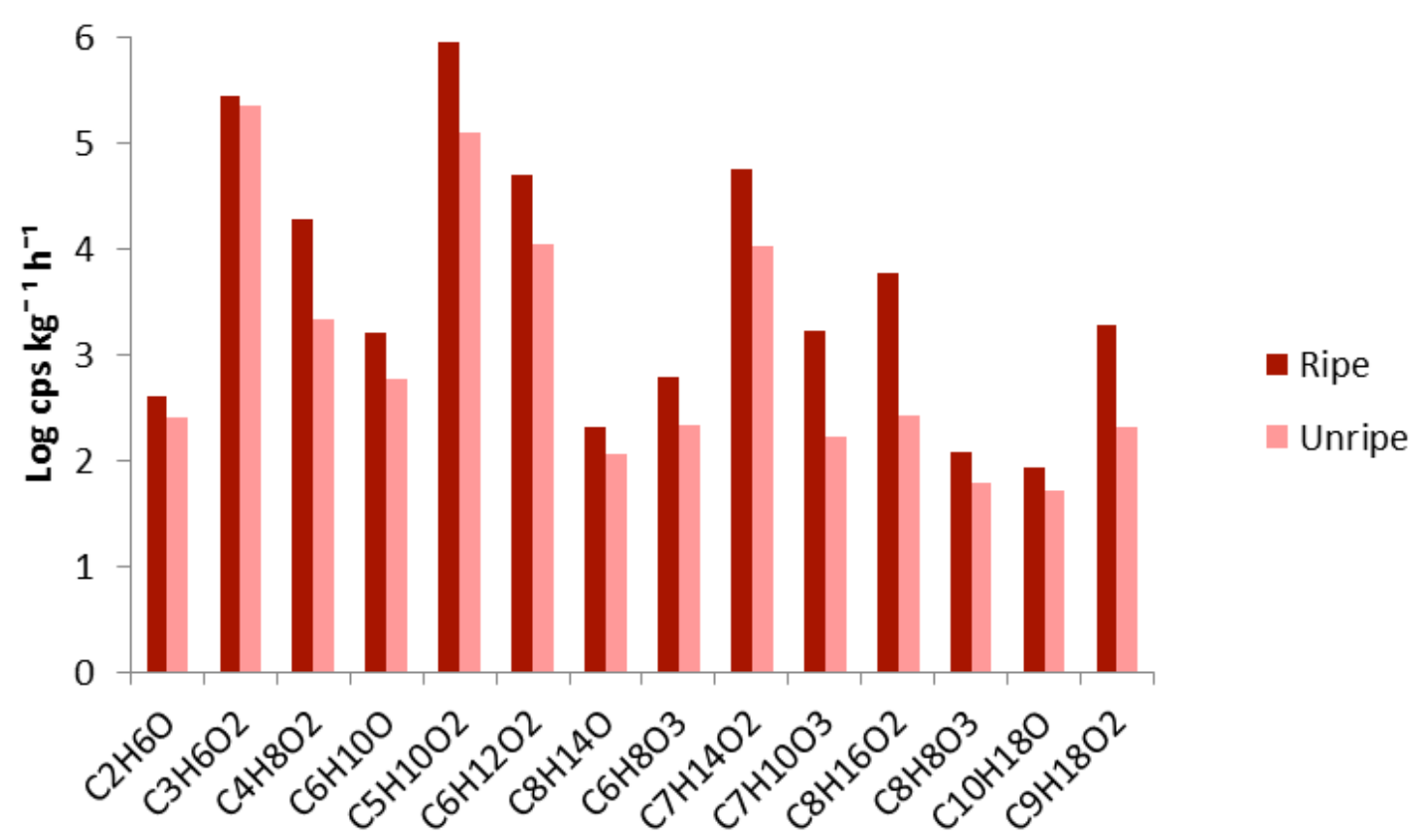

Figure 3.4. The concentration in log counts per seconds per $\mathrm{kg}$ per $\mathrm{h}$ as function of the expected molecular masses. In red the average ripe and in pink the average unripe strawberry. The isotopic mass of the expected molecular formula is visualised, which is a mass at approximately 1.008 higher its monoisotopic mass $+1 \mathrm{H}^{+}$. Concentrations are not representative, but give an indication of the ratio.

Table 3.1. The molecular formulas that were found for the average ripe and unripe strawberry mass spectra with the expected volatiles and their classes. Some molecular formulas represent both esters and acids. This could be the case with more molecular formulas.

\begin{tabular}{|c|c|c|}
\hline $\begin{array}{l}\text { Molecular } \\
\text { formula }\end{array}$ & Expected volatiles & Class \\
\hline $\mathrm{C}_{2} \mathrm{H}_{6} \mathrm{O}$ & Ethanol & Alcohol \\
\hline $\mathrm{C}_{3} \mathrm{H}_{6} \mathrm{O}_{2}$ & Methyl acetate & Ester \\
\hline $\mathrm{C}_{4} \mathrm{H}_{8} \mathrm{O}_{2}$ & Ethyl acetate & Ester \\
\hline $\mathrm{C}_{6} \mathrm{H}_{10} \mathrm{O}$ & Trans-2-hexenal & Aldehyde \\
\hline $\mathrm{C}_{5} \mathrm{H}_{10} \mathrm{O}_{2}$ & Methyl butanoate, ethyl propionate, 2-Methylbutanoic acid & Ester, ester, acid \\
\hline $\mathrm{C}_{6} \mathrm{H}_{12} \mathrm{O}_{2}$ & Ethyl butanoate, Butyl acetate, Hexanoic acid & Ester, ester, acid \\
\hline $\mathrm{C}_{8} \mathrm{H}_{14} \mathrm{O}$ & Trans-2-octenal & Aldehyde \\
\hline $\mathrm{C}_{6} \mathrm{H}_{8} \mathrm{O}_{3}$ & Furaneol & Furanone \\
\hline $\mathrm{C}_{7} \mathrm{H}_{14} \mathrm{O}_{2}$ & Methyl hexanoate, Ethyl isovalerate, isoamyl acetate & Ester \\
\hline $\mathrm{C}_{7} \mathrm{H}_{10} \mathrm{O}_{3}$ & Mesifurane & Furanone \\
\hline $\mathrm{C}_{8} \mathrm{H}_{16} \mathrm{O}_{2}$ & Ethyl hexanoate, butyl butanoate, hexyl acetate & Ester \\
\hline $\mathrm{C}_{8} \mathrm{H}_{8} \mathrm{O}_{3}$ & Methyl salicylate & Ester \\
\hline $\mathrm{C}_{10} \mathrm{H}_{18} \mathrm{O}$ & Linalool, alpha-Terpineol, Trans-2-geraniol & Terpenoid \\
\hline $\mathrm{C}_{9} \mathrm{H}_{18} \mathrm{O}_{2}$ & Ethyl heptanaote, heptyl acetate & Ester \\
\hline
\end{tabular}




\section{PTR and taste attributes}

PLS regression analyses the relation between the two data matrixes, one with all detected masses by the PTR (spectrum) and other with the scores of the 21 taste attributes obtained by the expert panel.

While the variation for the volatile data was the same as the earlier described PCA ( $84 \%$ by ripeness and $7 \%$ by storage time), the taste attributes scores showed a similar pattern variation; $49 \%$ by ripeness and $10 \%$ by storage time (Figure 3.5 ).

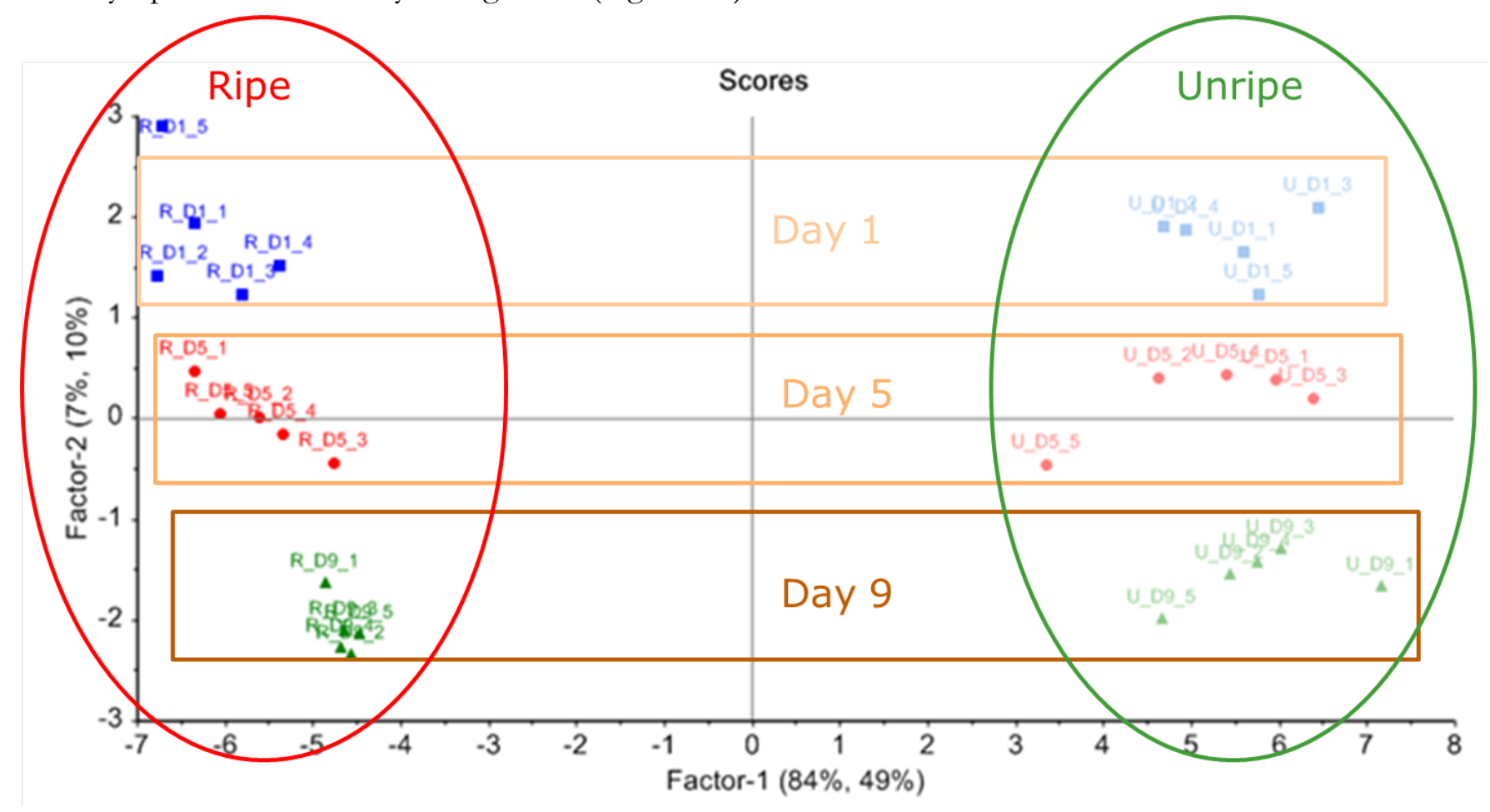

Figure 3.5. Scores of the PLS for PTR data and taste attributes. The main variation is between ripeness level and the second most variation is between storage days. In blue the samples of day 1 (ripe in dark blue, unripe in light blue, in red the samples of day 5 (ripe in dark red, unripe in light red), and in green the samples of day 9 (ripe in dark green, unripe in light green).

The correlation loadings plot presented in figure 3.6 reveals the relation between the taste scores and the measured volatiles. The position of these variables relatively to the samples (= maturity stage and shelf life) is done by combining the graph of figure 3.5 with figure 3.6. Variables on the left side are related to ripe strawberries and on the right side to unripe strawberries as shown in figure 3.5. 
Taste attributes linked to ripe strawberries include: aroma presence, sweetness, strawberry aroma, fruity aroma, aroma likening and juiciness. These 6 attributes are well related to several of the measured volatiles (figure 3.6; red circle). Taste attributes more correlated to unripe strawberries include: firmness, green aroma and sourness. These 3 attributes are highlighted in the green circle of figure 3.6. The figure also shows a limited number of volatiles which are present in higher concentration in unripe strawberries. Mealiness and yeast are correlated to strawberries with longer storage time (day 9), particularly for the ripe strawberries.

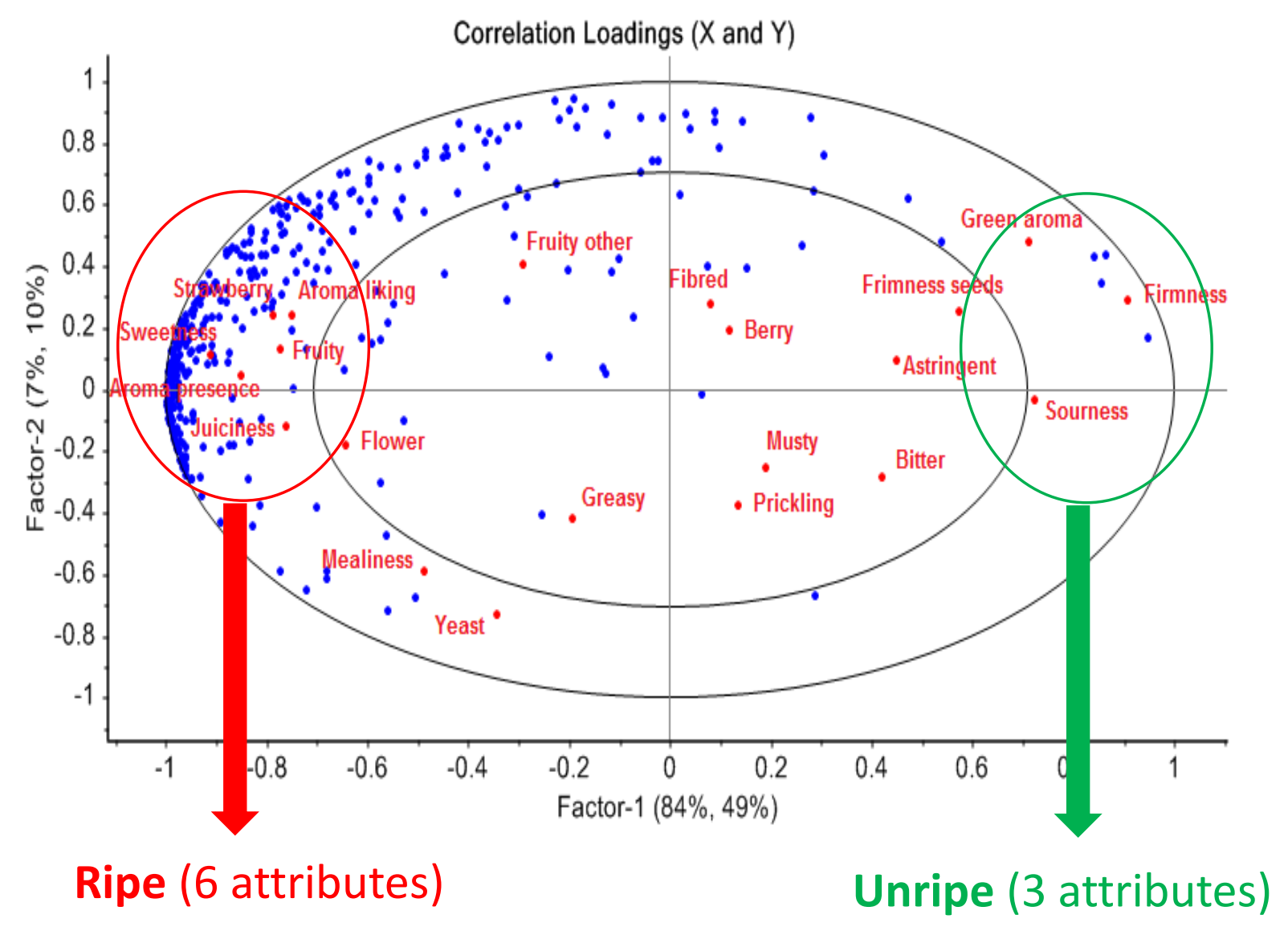

Figure 3.6. Correlation Loadings ( $\mathrm{X}$ and $\mathrm{Y}$ ) of PTR volatiles (blue dots) and taste attributes (red dots with names). Dots outside the inner circle significantly contribute to the variation. Ripe strawberries score higher for the attributes and volatiles highlighted in the red circle; unripe strawberries score higher for the attributes and volatiles highlighted in the green circle.

\subsection{Other quality aspects}

\section{Appearance and decay}

Figure 3.7 shows the scores for 3 quality aspects: punnet general appearance, the calyx freshness and fruit decay (amount of dry bruises, wet bruises and development of rot). 
Ripe strawberries decreased in their appearance, while the unripe strawberries increased in their appearance with a longer storage time. For appearance an interaction was found for the factors ripeness and storage time $(\mathrm{p}<0.001)$. The calyx freshness showed no differences between ripeness level or over storage time. Ripe strawberries showed more decay compared to unripe strawberries and both increased over storage time. For ripe fruits the decay at day 5 and 9 was higher than at day $1(\mathrm{p}<0.001)$ and for unripe the decay at day 9 was higher than at day 1 $(\mathrm{p}=0.011)$.

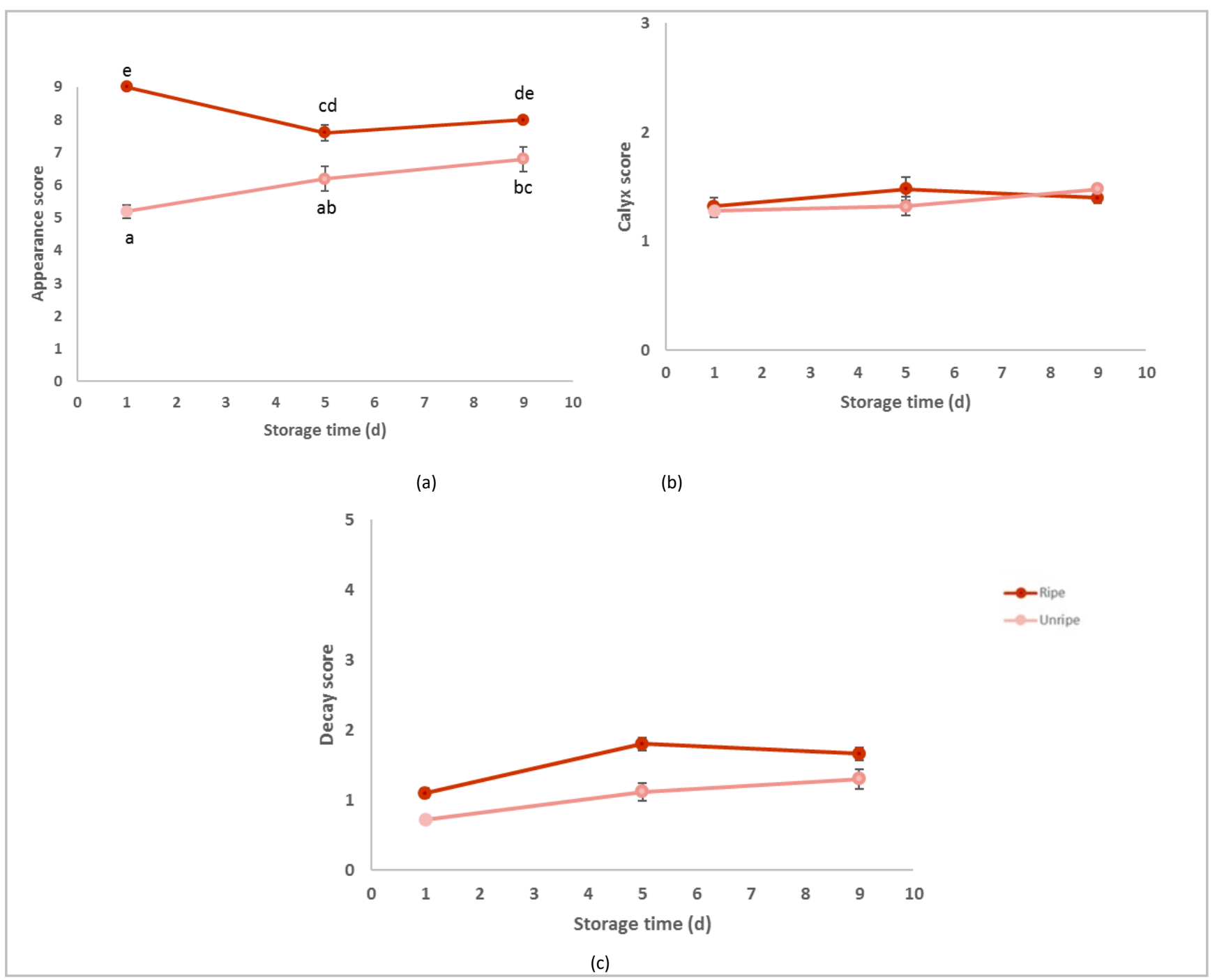

Figure 3.7. Appearance (a), calyx (b) and decay (c) scores for ripe and unripe strawberries as function of storage time in days (d) (red=ripe, pink = unripe). Averages $(n=5)$ are shown with $\pm S E$. The letters on graph (a) show the interaction between ripeness and storage time (Two-way ANOVA). Samples with the same letters are not significant different. Results of the statistics for the decay and Calyx are described on the text. 


\section{Firmness}

Figure 3.8 shows the results of the firmness measurements. Unripe strawberries were firmer than ripe strawberries $(\mathrm{p}<0.001)$. The firmness of unripe strawberries also decreased over storage time. At day 1 the firmness was significantly higher than on day $9(\mathrm{p}=0.002)$ (Figure 3.8). The decrease in firmness of ripe strawberries over the storage time is not statistical significant.

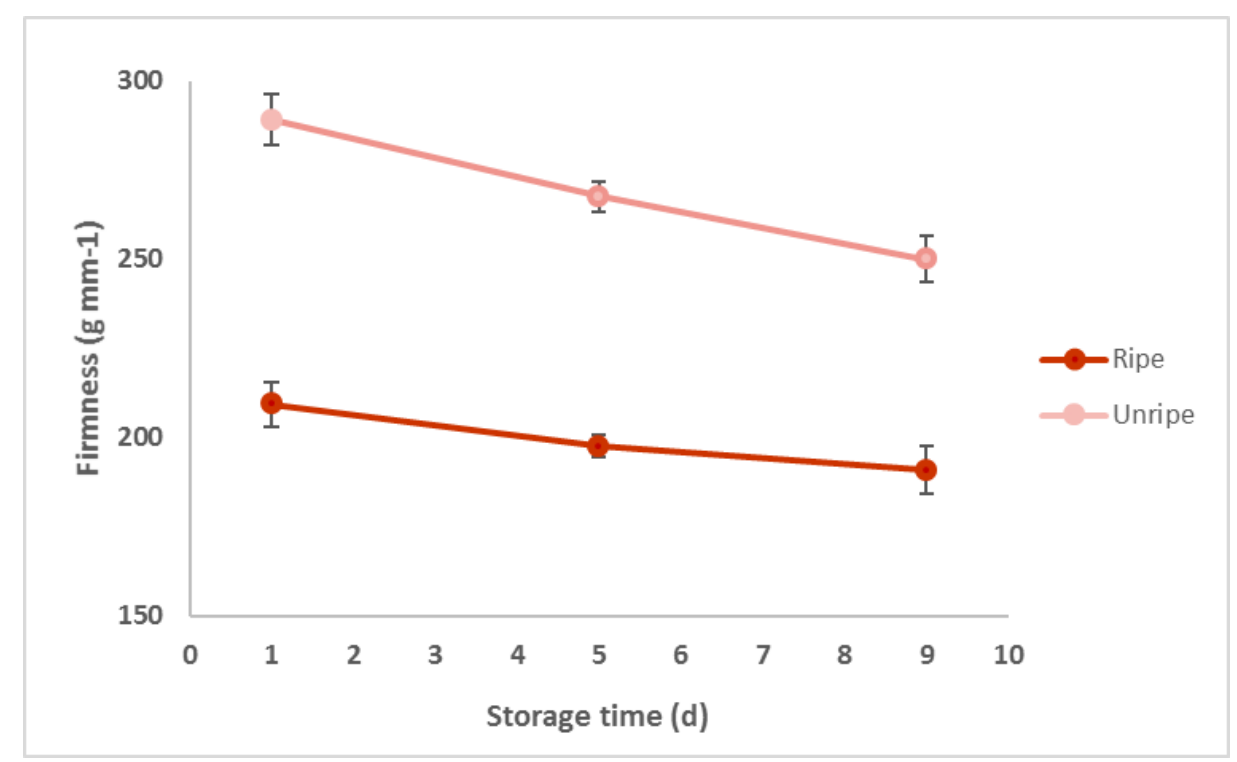

Figure 3.8. Firmness $\left(\mathrm{g} \mathrm{mm}^{-1}\right)$ for ripe and unripe strawberries as function of storage time in days (d) (red=ripe, pink = unripe). Averages $(n=5)$ are shown with $\pm S E$.

\section{Colour}

The hue is one of parameters of the cylindrical HSL (Hue, Saturation, Lightness) colour system. The hue is calculated in degrees starting at the red primary at $0^{\circ}$, passing through the green primary at $120^{\circ}$ and the blue primary at $240^{\circ}$, and then wrapping back to red at $360^{\circ}$. The higher the Hue the redder the colour. The area red and white represents the absolute amount of respectively red and white pixels measured. Therefore the area white or red depends on the size of the strawberries and consequently these measurement show higher variation. However since 15 strawberries were used for the measurements the total size of the sample should be approximately the same for all samples.

For the hue red value an interaction was found for the factors ripeness and storage time $(p<0.001)$. Unripe strawberries increased, while the ripe strawberries did not significantly change their hue red value over storage time. At day 9 the hue red value of unripe strawberries was higher compared to day $1(\mathrm{p}<0.001)$ and day $5(\mathrm{p}=0.004)$ (Figure 3.9a).

The hue white value $(\mathrm{p}<0.001)$ and the area white $(\mathrm{px})(\mathrm{p}=0.003)$ were higher for unripe strawberries (Graph 3.9 b and 3.10 b), while the area red $(p x)(p<0.001)$ was higher for ripe strawberries (Figure 3.10 a). 


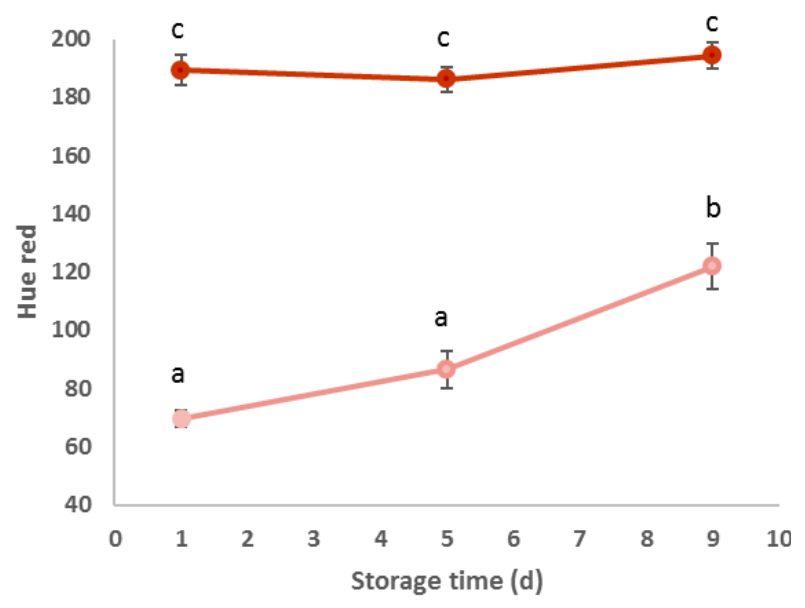

(a)

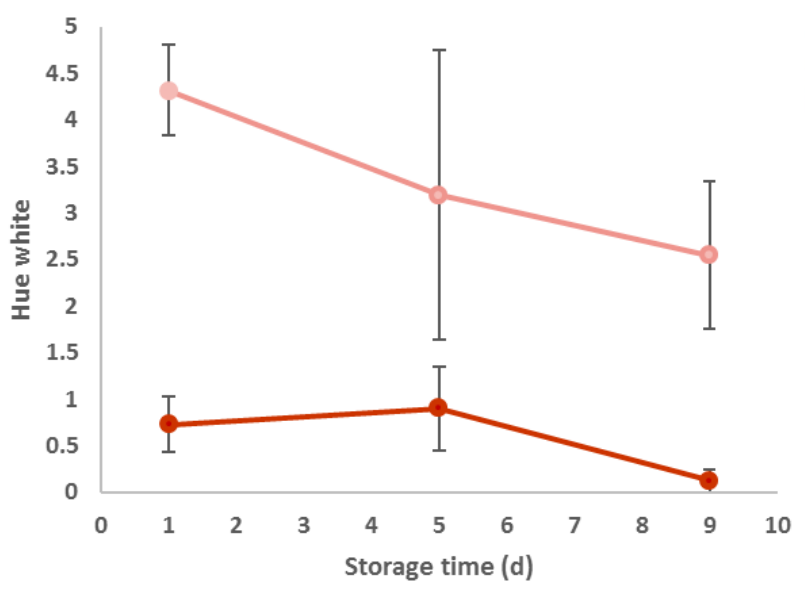

(b)

Figure 3.9. Hue red (a) and hue white (b) values for ripe and unripe strawberries as function of storage time in days (d) (red=ripe, pink = unripe). Averages $(n=5)$ are shown with \pm SE. The letters on graph (a) show the interaction between ripeness and storage time (Two-way ANOVA). Samples with the same letters are not significant different. Results of the statistic for the Hue white are described on the text.

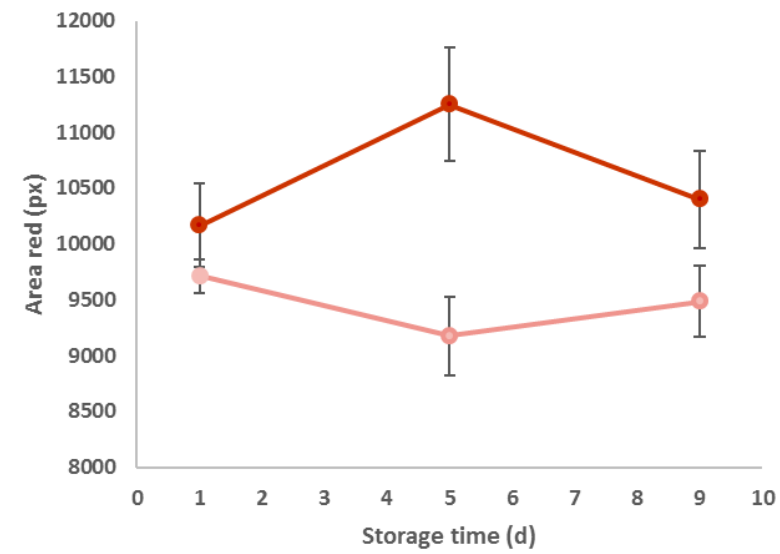

(a)

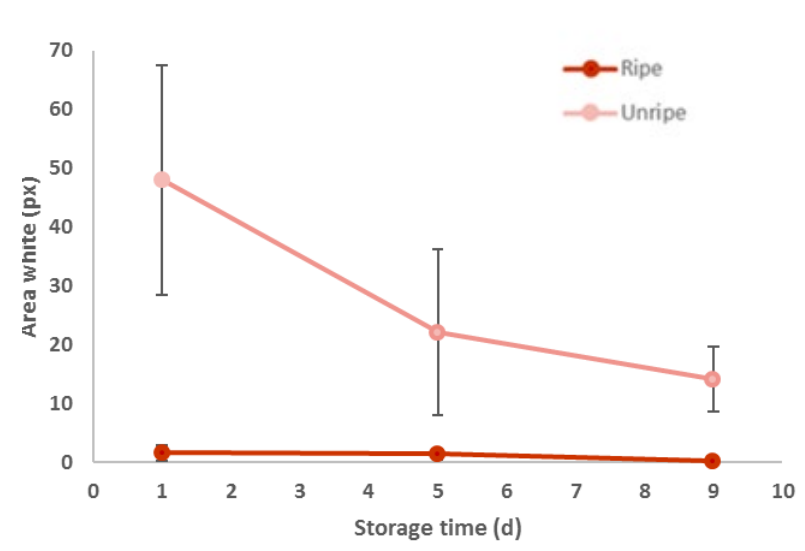

(b)

Figure 3.10. Area red (px) (a) and area white (px) (b) for ripe and unripe strawberries as function of storage time in days (d) (red=ripe, pink = unripe). Averages $(n=5)$ are shown with $\pm S E$.

\section{Soluble Solid Content (SSC)}

Ripe strawberries showed a higher SSC ( ${ }^{\circ}$ brix) content compared to unripe strawberries $(\mathrm{p}<0.001)$. When considering both ripe and unripe samples together the storage time also showed an effect because in both cases the SSC slightly decreases $(p=0.025)$ (Figure 3.11). When analysing the SSC values for the ripe and unripe samples separately no significant difference were found between the different storage days for both maturity stages. 


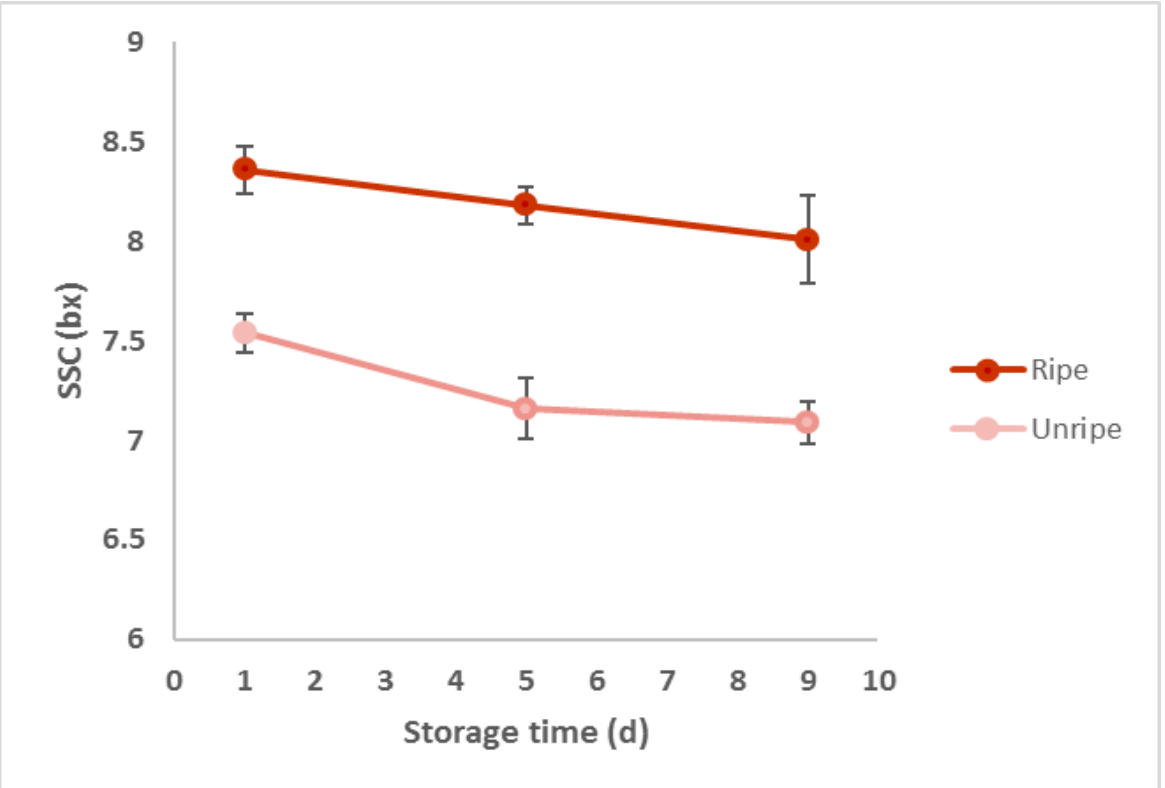

Figure 3.11. SSC ( ${ }^{\circ}$ brix) for ripe and unripe strawberries as function of storage time in days (d) (red=ripe, pink = unripe). Averages $(n=5)$ are shown with $\pm S E$.

\section{Acid}

The acid $\%$ was significant higher for unripe strawberries compared to ripe strawberries $(\mathrm{p}=0.002)$. When considering both ripe and unripe samples together the storage time also showed an effect; acid $\%$ is higher at day 1 compared to day $5(\mathrm{p}=0.004)$ (Figure 3.12). Regarding the storage time within each maturity stage, unripe strawberries showed a significant increase in acid $\%(p=0.042)$ while ripe strawberries showed no significant increase in acid $\%$ over the storage time. 


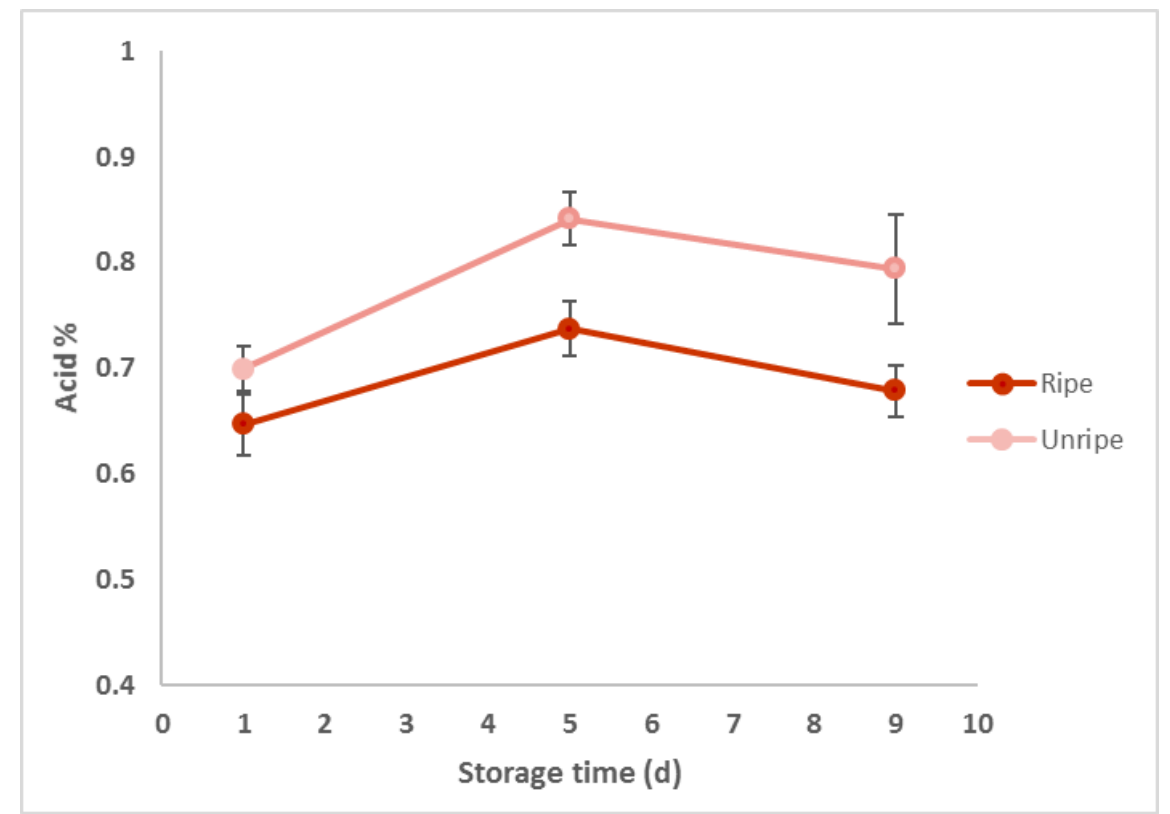

Figure 3.12. Acid\% for ripe and unripe strawberries as function of storage time in days (d) (red=ripe, pink = unripe). Averages $(n=5)$ are shown with \pm SE.

\subsection{Taste and other quality aspects}

PCA analysis of the taste attributes together with the other quality measurements (without PTR data) showed that most of the variation was explained by ripeness $(59 \%)$ and differences in storage time (19\%) (Figure 3.13). The bi-plot in figure 3.13 further shows how differences in ripeness and shelf-life relate to the measured variables. For example, sample R_D1 connects to higher SSC and fruity aroma values (lower right) and lower acid \% values (upper left). 


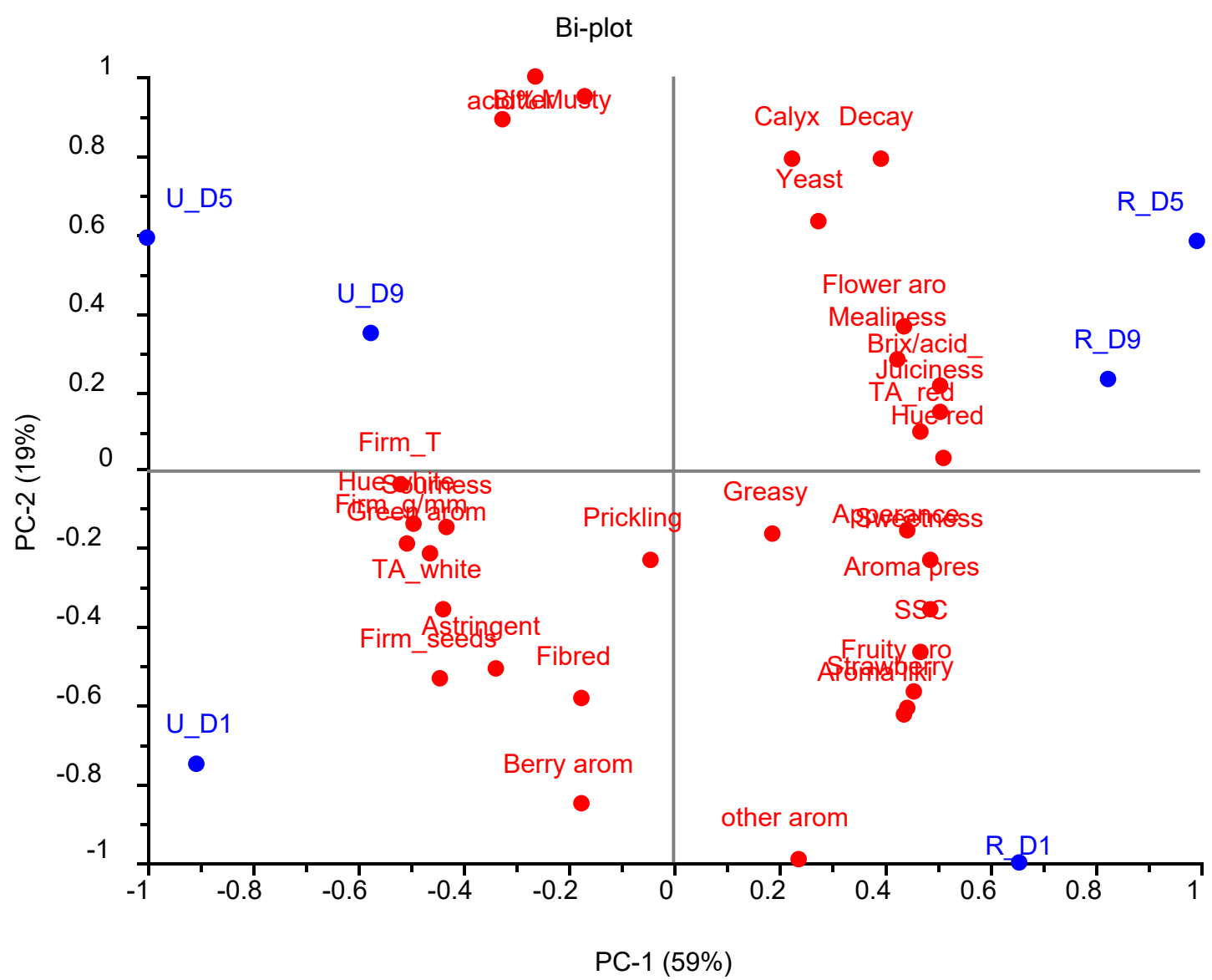

Figure 3.13. PCA Bi-plot of the taste attributes and other quality measurements. Data was analysed with averages per treatment. In blue the different treatments and in red the different taste attributes and other quality measurements. PC- 1 explains $59 \%$ of the variation and PC-2 19\%.

The correlation loadings plot presented in figure 3.14 reveals the relation between the taste scores and the other quality aspects. The taste attributes: strawberry aroma, aroma presence, aroma liking, sweetness and fruity aroma are particularly relate to the SSC (brix). Juiciness is more related to the ratio Brix/acid and the Hue red colour (red circle, figure 3.14). These variables are all higher in ripe compared to unripe strawberries.

On the other hand, the taste attributes firmness and green aroma are related with the firmness measured instrumentally (Firm_g/mm) and with the Hue_white colour. The sourness and total area white (TA-white) show some relation with each other and the previous variables (green circle, figure 3.14). These variables are all higher in unripe compared to ripe strawberries. 
Calyx and decay scores and the taste attribute "yeast" correlated with longer storage times and ripe strawberries. Acid\%, bitter and musty aromas were also correlated with longer storage time, but stronger in unripe strawberries. Berry aroma and fruity other aroma correlated with short storage times, berry aroma correlated stronger with unripe and "fruity other" aroma correlated stronger with ripe strawberries.

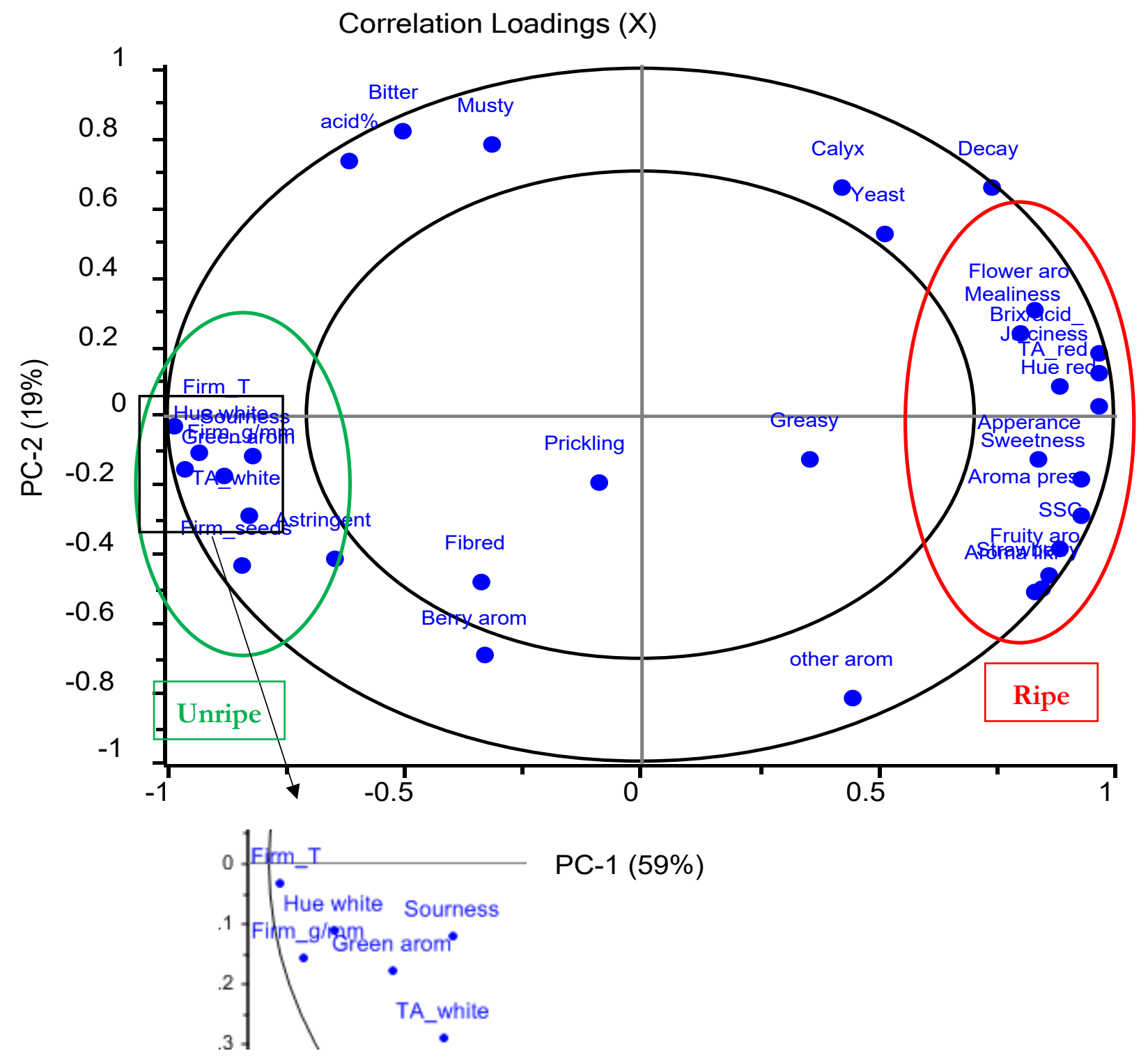

Figure 3.14. Correlation Loadings $(\mathrm{X})$ of taste and other quality aspects data. Components outer circle have a significant contribution to the variation in the data. 


\subsection{Taste model measurements and taste evaluation industry}

Wageningen Plant Research (Bleiswijk, The Netherlands) developed a taste model to assess the taste and flavour level of strawberries. This model works with a number of input parameters for basic flavour characteristics that are measured in the laboratory and gives a taste score on a scale from 1 to 100 (the higher the score the better the flavour/taste).

The differences between ripe and unripe samples and over the storage time in the taste model results were limited (figure 3.15). Since only one sample was measured, no statistical analysis was possible. However according to the knowledge and experience of the Wageningen Plant Research group a difference of $4-5$ score points is not significant.

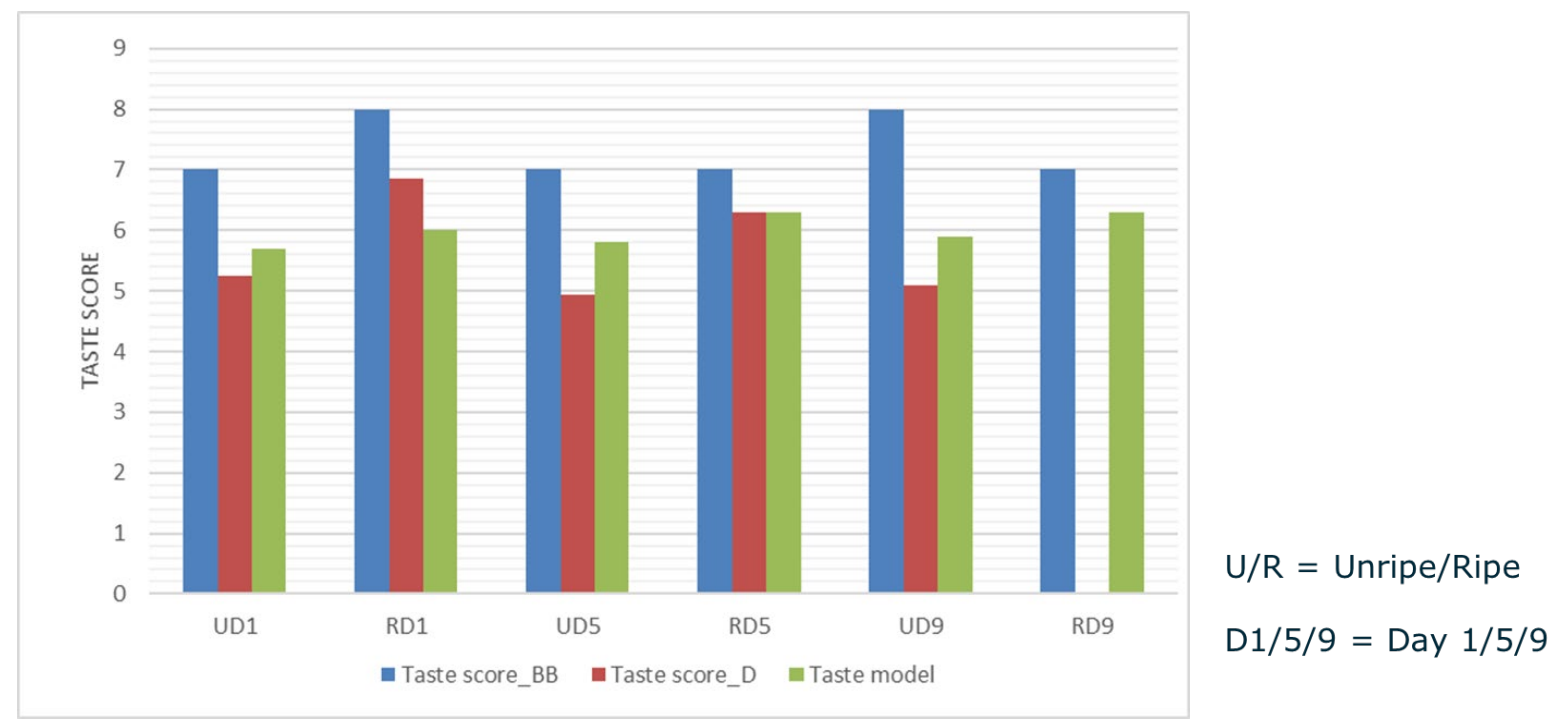

Figure 3.15. Taste score of three evaluation methods: Taste score_BB (blue) originating from the evaluation of the company Bakker Barendrecht; Taste score_D (red) from the evaluation of the company Driscoll's and Taste model (green) from the taste model measurements of Wageningen Plant Research. These last scores were dived by 10 to plot all the results more clearly in the same graph.

Regarding the Driscoll's results, the ripe samples had a higher score than the unripe samples and this difference was the same for both day 1 and 5 (the score of day 9 for the ripe samples is missing). The taste score of the ripe strawberries on day 5 was lower than on day 1 . On the opposite the taste score of the unripe samples did not change over the storage period.

The Bakker Barendrecht score taste of the ripe samples was higher, equal and lower than the unripe samples for day 1, 5 and 9 respectively. The ripe samples showed the highest score at day 1. Day 5 and 9 were lower and the same. The unripe samples had the same score on day 1 and 5 and the highest score on day 9. 


\section{Discussion}

\section{Effect of ripening and storage time on taste perception}

The significant differences in scores between the ripe and unripe samples clearly show the relevance of the maturity stage in flavour and taste perception (figure 3.1). Positive attributes such as strawberry aroma, aroma liking, sweetness, juiciness, fruity aroma and aroma presence score higher in ripe strawberries, indicating that optimally mature strawberries should lead to a more pleasant taste perception. As expected, unripe strawberries score higher on firmness, sourness, green aroma, astringent and bitter. These attributes are consistent with each other and show that the ripeness level results in a distinct flavour profile.

The changes in flavour and taste perception along the shelf life are rather different for ripe and unripe strawberries. Ripe strawberries lose strawberry aroma and are less liked. Unripe strawberries are perceived as even less sweet. In addition, the score of strawberry aroma, fruity aroma, aroma presence and likening of unripe strawberries does not increase over storage time. These results are in accordance with a non-climacteric fruit behaviour. Despite their colour changes and loss of firmness strawberries are considered non-climacteric fruits and therefore are not able to continue their ripening processes when detached from the plant (Kader, 1999). The development of fruity aromas does not increase during storage, hence these aromas will not become as present as in ripe strawberries (Perkins-Veazie, 1995). This indicates that taste perception does not improve during shelf life making the maturity stage at harvest essential to achieve high quality tasting strawberries. Table 4.1 summarises the changes over the shelf life of positive and negative attributes for ripe and unripe fruits.

Table 4.1. Overview of attributes changes during shelf life. Attributes that increase over time are marked with an arrow upwards ( $\uparrow$ ), decrease over time is marked with an arrow downwards $(\downarrow)$ and non-significant changes are marked with ns. Taste attributes with asterisk and $\sim$ did not show a clear trend. Attributes considered positive are highlighted in pink and negative ones in green.

\begin{tabular}{|ccc|}
\hline & RIPE & UNRIPE \\
Strawberry aroma & $\downarrow$ & ns \\
Aroma presence & ns & ns \\
Aroma liking & $\downarrow$ & $\sim$ \\
Fruity aroma & ns & $\sim$ \\
Sweetness & ns & $\downarrow$ \\
Sourness & ns & $\uparrow$ \\
Bitter & $\sim$ & ns \\
Green aroma & ns & $\downarrow$ \\
Musty & $\uparrow$ & ns \\
Yeast & $\uparrow$ & ns \\
Mealiness & ns & $\uparrow$ \\
\hline
\end{tabular}


Additionally, not only positive taste and flavour attributes change during shelf life but ripe strawberries become musty and yeasty. Particularly this last attribute may be the result of over ripening and fermentation typical of decay metabolism (Larsen and Watkins, 1995).

\section{Assessment of taste perception with PTR-Qi-TOF}

Volatile masses measured with the PTR-Qi-TOF showed clear differences between ripeness levels and storage days (figure 3.5 and 3.6). An abundance of volatile masses were correlated with ripe strawberries, while less volatile masses were correlated with unripe strawberries. The effect of maturity stage on the volatiles fingerprint (PTR spectrum) is much stronger than the shelf life.

Comparison of the volatiles with the taste attributes showed that the ripe strawberries were correlated with the aroma presence, strawberry aroma, sweetness, juiciness, fruity aroma and aroma likening, while unripe strawberry were correlated with firmness, green aroma and sourness. Longer storage time of ripe strawberries connected to mealiness and yeast. These results are in accordance with the ripening process. Most volatiles produced by strawberries are esters, which increase during ripening and are responsible for fruity aromas. The characteristic strawberry aroma is only fully present at the ripe stage and firmness and sourness decrease during ripening (Jetti et al., 2007; Perkins-Veazie, 1995; Schwab et al., 2008). Longer storage times of ripe strawberries correlate to mealiness and yeast. As noted previously, yeast taste may be linked to the increase in anaerobic respiration when strawberries decay (Larsen and Watkins, 1995). Mealiness is associated with loss of firmness and tissue senescence that may be expected upon longer storage time (Brummell et al., 2004).

The graphs in figure 4.1 give an indication of the correlation between the PTR spectrum and some attributes. The figure shows the relation between the trained expert panel score and score predicted by the PLS model based on the PTR spectrum (cross validation result). The cross validation procedure consist of the following steps: one sample is kept out of the model; the model is built with the remaining samples and finally the spectrum of the sample left aside is used to calculate the score of the attribute. This procedure leads to optimistic results and can therefore only be used to give an indication for the performance of the model.

The attributes Sweetness, strawberry aroma, aroma presence and green aroma showed the highest correlation coefficients (r-square ranging from 0.80 to 0.61 ) indicating that the correlation between the PTR spectrum and these attributes is very reasonable. The discontinuity of the current data set consisting of a group of high and low samples may lead to higher correlation coefficients, therefore these values should be revalidated with a better balanced data set. Further research is necessary to increase the number of samples to balance and improve the model and validate its performance with a new set of samples. 

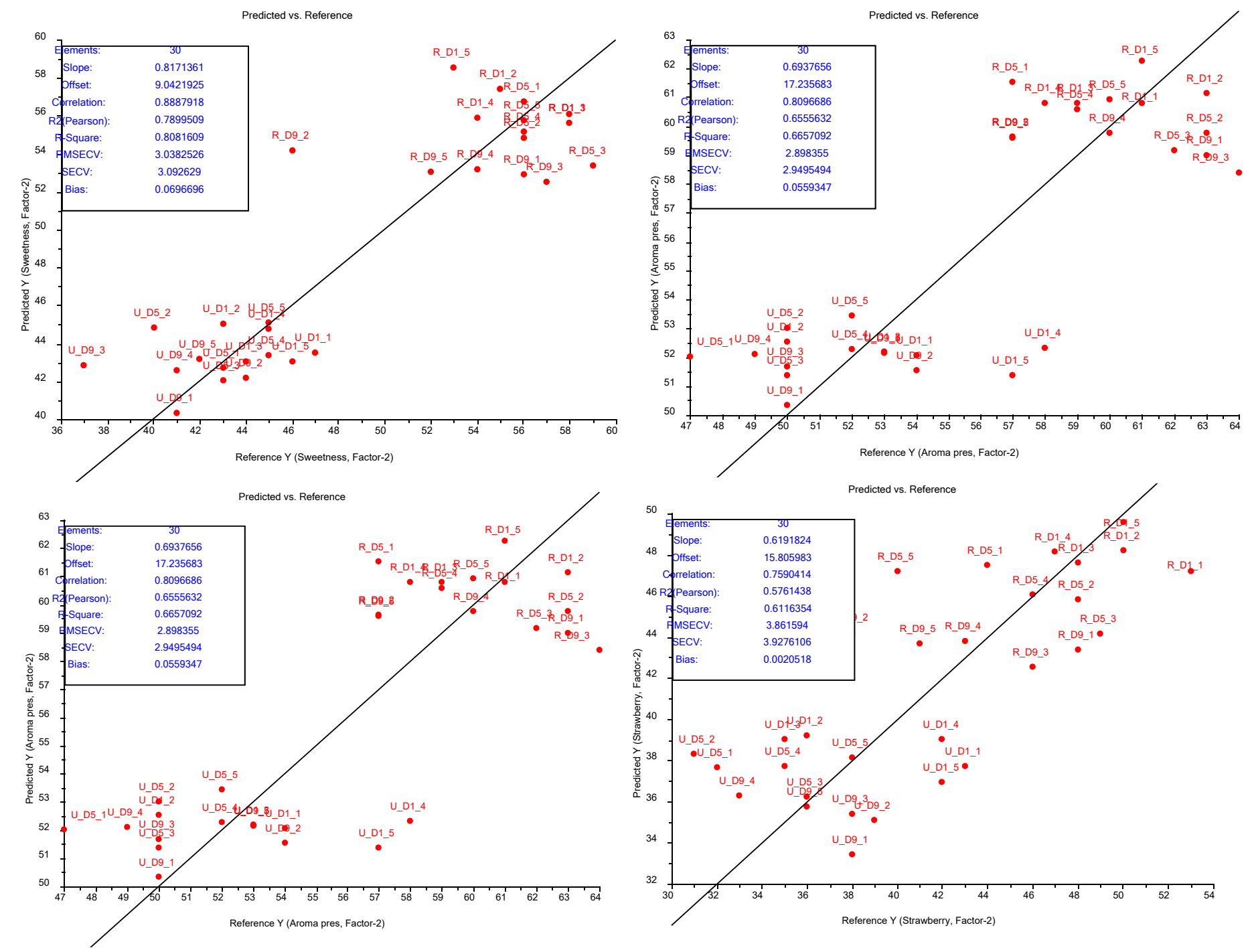

Figure 4.1. Relation between the expert panel score and score predicted by the PLS model based on the PTR spectrum (cross validation result); The r-Square value gives an indication of the correlation between the PTR spectrum and some attributes (the higher the better the correlation). 


\section{Volatiles}

Some of the volatile masses detected using the PTR Qi-TOF MS were tentatively identified based on earlier strawberry volatile studies (Jetti et al., 2007; Schwab et al., 2008; Vandendriessche et al., 2013). Some of the volatiles that showed increased presence in ripe strawberries (figure 3.4) may have an important contribution to the strawberry flavour, including the esters ethyl acetate, methyl butanoate, ethyl butanoate, ethyl isovalerate, methyl hexanoate and ethyl hexanoate, the furanones furaneol and mesifurane, and the terpenoid linalool. Since the PTR Qi-TOF only separates volatiles based on mass, an additional Gas Chromatography-MS (GC-MS) analysis is needed to confirm the detected volatiles. Different volatiles and volatile classes can have the same mass. This is the case with the esters ethyl butanoate and butyl acetate and the acid hexanoic acid, all having the molecular formula $\mathrm{C}_{6} \mathrm{H}_{22} \mathrm{O}_{2}$. The GC-MS analysis is not yet performed, therefore the found volatiles cannot be confirmed.

\section{Effect of ripening and storage time on other fruit quality aspects}

From the other fruit quality aspects it was found that ripe strawberries are significantly less firm, less white (both Hue as the total area), more total red area, more sweet (higher SSC), less acid and have a higher decay score. There is no difference between calyx appearance. This is in accordance to the results of previous research carried out within this project.

Unripe strawberries became less firm and the hue red value increased over time, while the ripe strawberries did not change firmness of their hue red value over storage time. Due to the high variation within the samples the hue white is not significant different over time for the unripe strawberries and neither for the ripe strawberries. The area white or red depends on the size of the strawberries. Despite the fact that the number of measured strawberries constant was (15 berries) this might still have effect on the results, therefore a correction for the size is necessary to assure that eventual size differences between punnets will not add noise to the results.

The appearance score increased for unripe strawberries, which is in line with the increase in red colour and shows that the appearance is mainly judged on colour. For ripe strawberries the appearance slightly decreased. The appearance of ripe strawberries is higher than unripe. For both ripeness levels the decay score increased over storage time. Both these results could be explained by the decrease of quality due to biological reactions and microbial growth during storage (Ayala-Zavala et al., 2004).

The calyx appearance (freshness) did not change over the time for none of the maturity stages.

The SSC ( ${ }^{\circ}$ Brix) level does not change during shelf life for none of the maturity levels. The acid $\%$ does not change either for the ripe strawberries but for the unripe strawberries it is higher at day 9 than at day 1. 
As expected all studied quality aspects are related to each other since the ripening process clearly affects the colour, firmness, aroma development, sugar and acid concentration and the fruit decay over time. The PCA analysis shows a stronger relation between the positive aroma attributes and the amount of SSC. In addition juiciness is particularly related with the red hue value and the ratio brix/acid. Finally the firmness measured instrumentally is well correlated with the firmness assessment of the expert panel. And both parameters are related to the green aroma and the hue white. These aspects are higher by the unripe than by the ripe strawberries and therefore the relationship is identified in the PCA analysis. 


\section{Conclusions and further research}

Based on the results it can be concluded that the PTR spectra correlate well with the expert panel scores. The taste attributes sweetness, strawberry aroma, aroma presence and green aroma showed the highest correlation coefficients ( $r$-square ranging from 0.80 to 0.61 ). This indicates that the correlation between the PTR spectrum and these attributes is very reasonable. Despite the shortcomings in the data (a separate group of high and low samples) that may lead to an overestimation of the results, this study has shown that the PTR-Qi-TOF MS is a potential technique to replace or complement the use of expert panels. Accordingly, this work is a first step into the development of a new objective technique to predict flavour and taste perception using PTR Qi-TOF MS.

Clear differences between ripeness level and storage time were found with both the PTR Qi-TOF MS and the expert panel. According to the PCA analysis it can be concluded that the difference in PTR spectra between the ripe and unripe strawberries is much bigger than the difference between the storage days within one maturity stage. This difference between maturity stage and storage time is less strong in the results of the expert panel. However the following is a clear conclusion of this study: the effect of the maturity stage on taste and flavour is far stronger than the storage time. Ripe strawberries correlated with pleasant fruity aromas, sweetness and an abundance of volatile masses. Unripe strawberries correlated with green aroma, sourness, firmness and not so many volatile masses. Mealiness and yeast correlate to strawberries that were stored longer (day 9), particularly for ripe strawberries. Some of the taste attributes do not seem to play a role in the fruit flavour description (greasy filming, prickling and fibred).

Based on this study it can be concluded that the maturity stage at harvest leads to distinct flavour profiles. Positive attributes score higher with ripe strawberries, indicating that an optimal maturity at harvest is essential to obtain high quality tasting strawberries. In addition taste perception of unripe strawberries does not improve during shelf life and never reaches the scores level of ripe strawberries. The changes in flavour and taste perception over the shelf life are rather different for ripe and unripe strawberries. Ripe strawberries lose strawberry aroma and are less liked. Unripe strawberries are perceived as even less sweet. The score of pleasant aromas of unripe strawberries does not increase over storage time. 
Regarding the other fruit quality aspects it can be concluded that ripe strawberries are less firm, less white (both Hue as the total area), larger total red area, more sweet (higher SSC), less acid and are more susceptible to decay than unripe strawberries. When considering changes in these quality aspects during shelf life it can be concluded that unripe strawberries undergo more changes: appearance, decay, hue_red, firmness \% acid, while in ripe strawberries only the appearance and decay change during shelf life (both decrease). Despites these physiological changes along the shelf life, unripe strawberries do not develop the ripe taste and flavour, as previously concluded.

Based on the current results, it can be concluded that the taste/flavour model is not suitable to assess the taste and flavour differences found between maturity stage and storage time. It should however be noticed that these measurements were done within the same cultivar and the same batch, whereas most research on the model has been done on discrimination between cultivars. This is also the main propose of the taste/flavour model. Moreover the development of the model is a long term project and improvements are still being done.

Further research is necessary to extend and validate the PTR-expert panel PLS model. New samples assessment is needed to balance and improve the model and to validate its performance with a complete new set of samples.

Each cultivar has a specific set of aromas and flavour and the perception by an expert panel is rather complex. The produced volatiles by Lusa correlate well with the scores of the expert panel. For other cultivars this relation might be different and therefore would need to be investigated. It is important to keep in mind that the odour detection thresholds differ among volatiles. For example, mesifurane is known for its low threshold value, so a relatively low concentration can have a strong contribution to the flavour. Furthermore, taste attributes do not necessarily have to be linked with high concentrations of certain volatiles. For example, the green aroma may be more noticeable due to the absence of the fruity aromas (Jetti et al., 2007).

Since there is a clear difference between ripeness levels, it is likely that certain volatiles strongly correlate with ripeness and specific taste attributes. A number of molecular weights that may have an important contribution to the strawberry flavour have been detected. Since the PTR QiTOF MS only separates volatiles based on mass, an additional Gas Chromatography-MS (GCMS) analysis is needed to confirm the detected volatiles. 


\section{References}

Ayvala-Zavala, J.F., Wang, S.Y, Wang, C.Y. and González-Aguilar, G.A. (2004). Effect of storage temperatures on antioxidant capacity and aroma compounds in strawberry fruit. LebensmittelWissenschaft \& Technologie, 37: 687-695.

Blake, R.S., Monks, P.S. and Ellis, A.M. (2009). Proton-Transfer Reaction Mass Spectrometry. American Chemical Society, 109: 861-896.

Brummell, D.A., Dal Cin, V., Lurie, S., Crisosto, C.H. and Labavitch, J.M. (2004). Cell wall metabolism during the development of chilling injury in cold-stored peach fruit: association of mealiness with arrested disassembly of cell wall pectins. Journal of Experimental Botany, 55(405): 2041-2052.

Buttery, R.G. (1981). Vegetable and fruit flavors. In: Teranishi, R., Flath, R.A. and Sugisawa, H. (editors). Flavor research: Recent advances, pp. 175-216. Marcel Dekker, New York.

Ionicon (2013). Technologies Overview. Proton Transfer Reaction - Mass Spectrometry Flyer. IONICON Analytik Gmbh. Online available at < http://www.ionicon.com/sites/default/files/uploads/downloads/flyer_2013_IONICON_PTRMS_technology_overview.pdf $>$. Accessed on 29-3-2017.

Ionicon (2016). PTR-QiTOF Factsheet. PTR-TOFMS series. IONICON Analytik Gmbh. Online available at

$<$ http://www.ionicon.com/sites/default/files/uploads/doc/flyer_2016_IONICON_ptrqitof.pdf $>$. Accessed on 28-3-2017.

Farneti, B., Cristescu, S.M., Cosat, G., Harren, F.J.M., and Woltering, E.J. (2012). Rapid Tomato Volatile Profiling by Using Proton-Transfer Reaction Mass Spectrometry (PTR-MS). Journal of Food Science, 77(5):551-559.

Forney, C.F., Kalt, W. and Jordan, M.A. (2000). The Composition of Strawberry Aroma Is Influenced by Cultivar, Maturity, and Storage. HortScience, 35(6): 1022-1026.

Jaeger, S.R., Hort, J., Porcherot, C., Ares, G., Pecore, S. and MacFie, H.J.H. (2017). Future directions in sensory and consumer science: Four perspectives and audience voting. Food Quality and Preference, 56: 301-309.

Jetti, R.R., Yang, E., Kurnianta, A., Finn, C. and Qian, M.C. (2007). Quantification of Selected Aroma-Active Compounds in Strawberries by Headspace Solid-Phase Microextration Gas Chromatography and Correlation with Sensory Descriptive Analysis. Journal of Food Science, 72(7): 487-496. 
Kader, A.A. (1991). Quality and its maintenance in relation to the postharvest physiology of strawberry. In: Dale, A. and Luby, J.J. (editors). The Strawberry into the 21 $1^{\text {st }}$, pp. 145-152. Timber Press, Portland, Oregon.

Kader, A.A. (1999). Fruit Maturity, ripening, and Quality Relationships. Acta Horticulturae. 485: 203-208.

Kafkas, E., Kosar, M., Paydas, S., Kafkas, S and Baser, K.H.C. (2007). Quality characteristics of strawberry genotypes at different maturation stages. Food Chemistry, 100: 1229-1236.

Larsen, M. and Watkins, C.B. (1995). Firmness and concentrations of acetaldehyde, ethyl acetate and ethanol in strawberries stored in controlled and modified atmospheres. Postharvest Biology and Technology, 5: 39-50.

Pelayo-Zaldivar, C., Ebeler, S.E. and Kader. A.A. (2005). Cultivar and harvest date effects on flavor and other quality attributes of California Strawberries. Journal of Food Quality, 28: 78-97.

Schwab, W., Davidovich-Rikanati, R. and Lewinsohn, E. (2008). Biosynthesis of plant-derived flavor compounds. The Plant Journal, 54: 712-732.

Smit, L.I. (2002). A tutorial on Principal Component Analysis. University of Otago, Computer Science department, New Zealand. Online available at

$<$ http://www.cs.otago.ac.nz/cosc453/student_tutorials/principal_components.pdf > Accessed on 4-4-2017.

Sulzer, P., Hartungen, E., Hanel, G., Feil, S., Winkler, K., Mutschlechner, P., Haidacher, S., Schottkowsky, R., Gunsch, D., Seehauser, H., Striednig, M., Jürschik, S., Breiev, K., Lanza, M., Herbig, J., Märk, L., Märk, T.D. and Jordan, A. (2014). A Proton Transfer Reaction-Quadrupole interface Time-Of-Flight Mass Spectrometer (PTR-QiTOF): High speed due to extreme sensitivity. International Journal of Mass Spectrometry, 36: 1-5.

Vandendriessche T., Geerts P., Membrebe B., Keulemans W., Nicolai B., Hertog M. (2013). Journeys through aroma space: a novel approach towards the selection of aroma-enriched strawberry cultivars in breeding programmes. Plant Breeding, 132 (2): 217-223.

Vandendriessche T., Vermeir S., Mayayo Martinez C., Hendrickx Y., Lammertyn J., Nicolai B., Hertog M. (2013). Effect of ripening and inter-cultivar differences on strawberry quality. LWTFood Science and Technology, 52: 62-70. 


\section{Acknowledgements}

Foundation TKI Horticulture, Driscoll's and Bakker Barendrecht are acknowledged for the project funding. We thank Driscoll's for supplying the strawberries and especially Rob van Mullem for the close collaboration. Finally we would like to express our gratitude to Nina Oud for carrying out several of the quality analysis and her contribution to the data analysis. 


\section{Appendices}

\section{Volatile masses}

Table 5.1. The molecular formulas that were found for the average ripe and unripe strawberry mass spectra. The monoisotopic mass ( $\mathrm{m} / \mathrm{z}$ ), the mass $(\mathrm{m} / \mathrm{z})$ in the PTR and the isotopic mass $(\mathrm{m} / \mathrm{z})$ in the PTR are given. Based on the monoisotopic mass the expected mass in the PTR was calculated by added the mass of $1 \mathrm{H}^{+}(1.007276 \mathrm{~m} / \mathrm{z})$ to the monoisotopic mass, because the PTR uses $\mathrm{H}_{3} \mathrm{O}^{+}$as proton transfer. The isotopic mass in the PTR was calculated by added 1 neutron $(1.00867 \mathrm{~m} / \mathrm{z})$ to the expected mass in PTR. The found isotopic mass for $\mathrm{C}_{8} \mathrm{H}_{14} \mathrm{O}$ is uncertain, since this mass is slightly different compared to expected isotopic mass.

\begin{tabular}{|c|c|c|c|c|c|}
\hline \multirow{2}{*}{$\begin{array}{c}\text { Molecular } \\
\text { formula } \\
\end{array}$} & \multirow{2}{*}{$\begin{array}{r}\text { Monoisotopic mass } \\
(\mathrm{m} / \mathrm{z})\end{array}$} & \multicolumn{2}{|c|}{ Mass $(\mathrm{m} / \mathrm{z})$ in PTR } & \multicolumn{2}{|c|}{ Isotopic mass $(\mathrm{m} / \mathrm{z})$ in PTR } \\
\hline & & Expected & Found & Expected & Found \\
\hline $\mathrm{C}_{2} \mathrm{H}_{6} \mathrm{O}$ & 46.0419 & 47.4914 & 47.048 & 48.0571 & 48.052 \\
\hline $\mathrm{C}_{3} \mathrm{H}_{6} \mathrm{O}_{2}$ & 74.0368 & 75.0441 & 75.044 & 76.0521 & 76.048 \\
\hline $\mathrm{C}_{4} \mathrm{H}_{8} \mathrm{O}_{2}$ & 88.0524 & 89.0597 & 89.059 & 90.0677 & 90.062 \\
\hline $\mathrm{C}_{6} \mathrm{H}_{10} \mathrm{O}$ & 98.0732 & 99.0804 & 99.080 & 100.0884 & 100.083 \\
\hline $\mathrm{C}_{5} \mathrm{H}_{10} \mathrm{O}_{2}$ & 102.0681 & 103.0754 & 103.075 & 104.0834 & 104.078 \\
\hline $\mathrm{C}_{6} \mathrm{H}_{12} \mathrm{O}_{2}$ & 116.0837 & 117.0910 & 117.09 & 118.0990 & 118.094 \\
\hline $\mathrm{C}_{8} \mathrm{H}_{14} \mathrm{O}$ & 126.1045 & 127.1117 & 127.111 & 128.1197 & 128.109 \\
\hline $\mathrm{C}_{6} \mathrm{H}_{8} \mathrm{O}_{3}$ & 128.0473 & 129.0546 & 129.055 & 130.0626 & 130.096 \\
\hline $\mathrm{C}_{7} \mathrm{H}_{14} \mathrm{O}_{2}$ & 130.0994 & 131.1067 & 131.106 & 132.1147 & 132.110 \\
\hline $\mathrm{C}_{7} \mathrm{H}_{10} \mathrm{O}_{3}$ & 142.0630 & 143.0703 & 143.070 & 144.0783 & 144.074 \\
\hline $\mathrm{C}_{8} \mathrm{H}_{16} \mathrm{O}_{2}$ & 144.1150 & 145.1223 & 145.123 & 146.1303 & 146.127 \\
\hline $\mathrm{C}_{8} \mathrm{H}_{8} \mathrm{O}_{3}$ & 152.0473 & 153.0546 & 153.054 & 154.0626 & 154.054 \\
\hline $\mathrm{C}_{10} \mathrm{H}_{18} \mathrm{O}$ & 154.1358 & 155.1430 & 155.142 & 156.1510 & 156.142 \\
\hline $\mathrm{C}_{9} \mathrm{H}_{18} \mathrm{O}_{2}$ & 158.1307 & 159.1380 & 159.139 & 160.1460 & 160.143 \\
\hline
\end{tabular}




\section{PTR Qi-TOF information}

In order to analyse which volatiles strawberry produces, PTR-MS (Proton Transfer Reaction - Mass spectrometer) is a useful instrument for real-time detection of volatiles with the capability to detect very low concentration without a sample preparation (Ionicon, 2013). A relatively new instrument in this category of PTR-MS is the PTR-Qi TOF (PTR-Quadrupole interface TimeOf-Flight MS).

Hydronium $\left(\mathrm{H}_{3} \mathrm{O}^{+}\right)$ions in gas phase are used as ion source reagents and undergo a fast Proton Transfer Reaction (PTR) in the drift tube of 3.8 mbar by $\mathrm{H}_{3} \mathrm{O}^{+}+\mathrm{R} \rightarrow \mathrm{RH}^{+}+\mathrm{H}_{2} \mathrm{O}$ with $\mathrm{R}$ the trace compounds (Blake et al., 2009; Ionicon, 2016) and thereafter analysed with the TOF-MS. The transfer region between the drift tube and the TOF-MS is different from the other PTR-MS instruments. Instead of a conventional transfer lens system that its predecessor contains, this instrument uses a quadrupole ion guide, which could transfer the ions more effectively (Sulzer et al., 2014). This has resulted in a 20 times higher sensitivity than its predecessor the PTR-TOF 8000 (Ionicon, 2016).

The time-of-flight MS works by deflecting the ionised compounds into the flight tube by an electric field. The ions will be accelerated by the electric field, which results in gaining a certain level of kinetic energy depending on their charge. Ions with the same charge receive the same kinetic energy, but depending on their mass the heavier ions will travel slower through the flight tube to the detector compared to the lighter ones. The compounds could be separated according to their flight times to the detector. Since the flight times are dependent on their mass and charge, the time-of-flight spectrum could be converted into a mass spectrum by using their massto-charge-ratio. This instruments is able to collect the whole mass spectrum at once. In this way, complex volatile mixtures could be analysed in real-time (Blake et al., 2009). Compounds with a lower proton affinity than water will not be ionised and therefore not be detected, which applies for common air compounds, such as $\mathrm{N}_{2}, \mathrm{O}_{2}$ and $\mathrm{CO}_{2}$. This is a reason why this instrument is very sensitive to detect trace compounds with a low detection limit (Ionicon, 2016).

It could be difficult to identify the individual volatiles of highly complex mixtures, such as strawberry. Since the separation of compounds fully relies on mass spectrometry, it could be possible that different compounds have the same mass-to-charge-ratio what it made impossible to identify the individual compounds. Also isotopic peaks of the corresponding volatile are visible and volatiles could be broken and it mass divided over different peaks. A solution is to combine the instrument with gas chromatography to distinguish the compounds by different retention times. However, this also takes more time (Sulzer et al., 2014). 


\section{Principal component analysis (PCA) information}

In order to understand PCA, some knowledge is required about matrixes, eigenvectors, and eigenvalues. A matrix is a rectangular set of elements arranged in rows and columns. Matrices could be linear transformed. A vector is an one column matrix, of which an eigenvector is a special case. The matrix A elongates the vector $\mathrm{x}$ without altering its direction. This makes $\mathrm{x}$ is the eigenvector of matrix $A$. This is visualized the following example and with figure 5.1, where $A$ represents the matrix of $\left(\begin{array}{ll}2 & 3 \\ 2 & 1\end{array}\right)$, x represents the eigenvector $\left(\begin{array}{l}3 \\ 2\end{array}\right)$ and $\lambda$ the eigenvalue of 4 . So, the eigenvalue is the value that could multiply $\mathrm{x}$.

Example of matrix with eigenvector and eigenvalue (Smit, 2002):

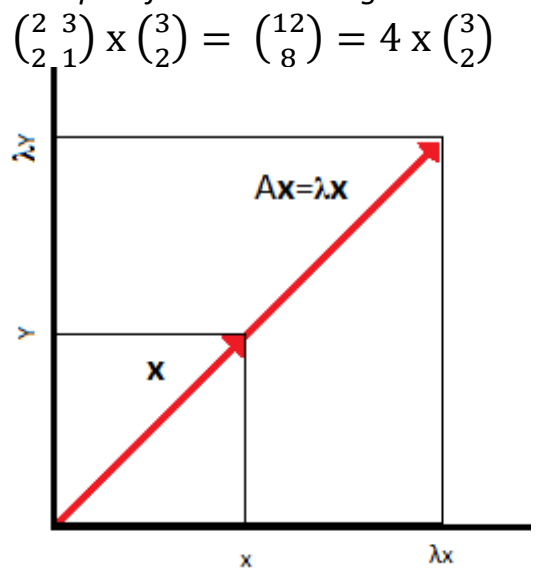

Figure 5.1. The linear transformation of matrix $A$ with its eigenvector $x$ and eigenvalue $\lambda$.

PCA is method to analysis patterns within multivariable datasets. It searches for their similarities and differences. The data could be compressed by reducing the number of dimensions without much information loss. The average per dimension is subtracted from each of the values of this dimension. Thereafter, the covariance matrix of the dataset is calculated followed by calculating the eigenvectors and eigenvalues. The eigenvector with the lowest eigenvalue explains most of the variation in the dataset (Smith, 2002)

\section{Partial least squares regression (PLS) information}

PLS regression analyses the relation between two matrixes, $\mathrm{X}$ and $\mathrm{Y}$; with $\mathrm{Y}$, one or several dependent variables or responses, and $\mathrm{X}$, a set of predictor variables. In case of analysing strawberry volatiles, $\mathrm{Y}$ could be the aroma components of different strawberries and $\mathrm{X}$ the chemical composition of volatiles in a strawberry.

PLS can analyse noisy, correlated data, which is useful since the variables in MS tend to be strongly correlated. The different Y's could be first separately analysed by using a PCA, which gives a good idea about the amount of systematic variation in $\mathrm{Y}$, which helps to indicate which Y's should be further analysed by a PLS. In PLS the X matrix is visualised by a group of $\mathrm{n}$ points in the $\mathrm{k}$ dimensional space on an hyperplane in a position that the coordinates give a good prediction of $\mathrm{Y}$ variables (Wold et al., 2001). 


\section{Karlruher Scheme}

Table 5.2. Karlruher Scheme used for the appearance score on a 1-9 scale.

\begin{tabular}{|c|c|c|}
\hline & \multicolumn{2}{|c|}{ Appearance } \\
\hline & Colour & Shape \\
\hline 9 - Excellent & $\begin{array}{l}\text { Exceptionally appealing, bright, } \\
\text { natural colour, typical for the } \\
\text { sample. }\end{array}$ & $\begin{array}{l}\text { Perfect preservation of shape, firm, } \\
\text { undamaged shape. }\end{array}$ \\
\hline 8 - Very good & $\begin{array}{l}\text { Bright natural colour, typical for the } \\
\text { sample, single slightly discoloured } \\
\text { specimen allowed. }\end{array}$ & $\begin{array}{l}\text { Very well preserved shape, single } \\
\text { slightly changed specimen. }\end{array}$ \\
\hline 7 - Good & $\begin{array}{l}\text { Natural colour, typical for sample, a } \\
\text { little too pale or too dark, a few } \\
\text { slightly discoloured specimen } \\
\text { allowed. }\end{array}$ & $\begin{array}{l}\text { Well preserved shape, a few slightly } \\
\text { or single strongly changed } \\
\text { specimen. }\end{array}$ \\
\hline 6-Satisfactory & $\begin{array}{l}\text { Slight reduction of typical colour } \\
\text { image, eg. Irregular light or dark. }\end{array}$ & $\begin{array}{l}\text { Still good preserved shape, a few } \\
\text { slightly or occasional strongly } \\
\text { damaged specimen. }\end{array}$ \\
\hline 5-Mediocre & $\begin{array}{l}\text { Impairment of typical colour, eg. } \\
\text { Slightly bleached, unbalanced. }\end{array}$ & $\begin{array}{l}\text { Impairment of natural shape, eg. } \\
\text { slight loss of shape, shrunken. }\end{array}$ \\
\hline 4 - Borderline & $\begin{array}{l}\text { Discolouration of sample surface, } \\
\text { eg. with stripes of other colour } \\
\text { nuances, not yet unpleasant. }\end{array}$ & $\begin{array}{l}\text { General loss of shape, shrunken, } \\
\text { still not unpleasant. }\end{array}$ \\
\hline 3 - Poor & $\begin{array}{l}\text { Strong discolouration of sample, eg. } \\
\text { blue or greyish. }\end{array}$ & $\begin{array}{l}\text { Generally serve loss of shape, } \\
\text { shrunken. }\end{array}$ \\
\hline $2-\mathrm{Bad}$ & $\begin{array}{l}\text { Complete discolouration of sample } \\
\text { surface, original colour no longer } \\
\text { perceptible. }\end{array}$ & $\begin{array}{l}\text { Severely changed shape. Still not } \\
\text { repulsive, advanced disintegration. }\end{array}$ \\
\hline 1 - Very bad & $\begin{array}{l}\text { Complete discolouration of sample } \\
\text { surface towards repulsive colours. }\end{array}$ & $\begin{array}{l}\text { Shape of sample has fully } \\
\text { disintegrated. }\end{array}$ \\
\hline
\end{tabular}

